\title{
MAGNITUDES DO FENÔMENO DA ILHA DE CALOR URBANA EM SACRAMENTO (MG): PERSPECTIVAS DE APLICAÇÃO DO SISTEMA DAS ZONAS CLIMÁTICAS LOCAIS EM CIDADE DE PEQUENO PORTE
}

\author{
Leandro de Godoi Pinton \\ Universidade Federal do Triângulo Mineiro, Docente do Departamento de Geografia, Uberaba, MG, Brasil \\ leandro.pinton@uftm.edu.br
}

Maria Clara Aparecida Ribeiro

Universidade Federal do Triângulo Mineiro, Discente do Curso de Licenciatura em Geografia, Uberaba, MG,

Brasil

mariaclaraapribeiro2010@gmail.com

Tainá Medeiros Suizu

Universidade Federal de Goiás, Doutoranda do Programa de Pós-Graduação em Ciências Ambientais, Goiânia,

$\mathrm{GO}$, Brasil

taina.suizu@hotmail.com

\begin{abstract}
Margarete Cristiane de Costa Trindade Amorim Universidade Estadual Paulista, Livre Docente do Departamento de Geografia e do Programa de Pós-Graduação em Geografia, Presidente Prudente, SP, Brasil margarete.amorim@unesp.br
\end{abstract}

\begin{abstract}
RESUMO
O presente estudo teve como objetivo avaliar as intensidades do fenômeno da ilha de calor urbana em Sacramento (MG), cidade de pequeno porte que integra a Região Imediata de Uberaba (MG), com base nos princípios do sistema de classificação das Zonas Climáticas Locais. A fim de atender tal proposição, realizou-se uma articulação entre os dados obtidos na escala local (medidas móveis da temperatura do ar e metadados das propriedades da cobertura da superfície) com aqueles representativos da dinâmica atmosférica regional, de modo que fosse possível apreender as respostas dos condicionantes urbanos ao ritmo climático. No plano teórico, a investigação foi amparada pelo paradigma do Sistema Clima Urbano. Sob condição atmosférica ideal, verificou-se a formação de ilha de calor urbana com magnitude grande $\left(5,1^{\circ} \mathrm{C}\right)$ entre paisagens com diferenças substanciais de morfologia e material de superfície. Ademais, existe uma expressiva compatibilidade na termodinâmica das classes mais representativas da área de estudo com os padrões térmicos reportados em cidades de baixas e médias latitudes. De modo geral, admite-se que este estudo configura a primeira aproximação do uso da estrutura divisional das paisagens em Zonas Climáticas Locais para a compreensão da ilha de calor urbana em cidade tropical brasileira de pequeno porte.
\end{abstract}

Palavras-chave: Climatologia Tropical. Climatologia urbana. Transectos móveis.

\section{MAGNITUDES OF URBAN HEAT ISLAND PHENOMENON IN SACRAMENTO (MG): PERSPECTIVES FOR APPLICATION OF THE LOCAL CLIMATE ZONES SYSTEM IN A SMALL CITY}

\begin{abstract}
The present study aimed to evaluate the intensities of urban heat island phenomenon in Sacramento (MG), a small city that integrates the Immediate Region of Uberaba (MG), based on the principles of the Local Climate Zones classification system. Articulation between the obtained data from the local scale (mobile air temperature measurements and metadata of the surface cover properties) with those representatives of the regional atmospheric dynamics was held to apprehend the responses of urban controls to the climatic rhythm. Regarding the theoretical framework, the investigation was supported by the paradigm of the Urban Climate System. Under ideal atmospheric conditions, a large urban heat island magnitude $\left(5.1^{\circ} \mathrm{C}\right)$ was observed between landscapes with substantial differences in surface morphology and fabric. Also, there is expressive compatibility in the thermodynamics of the most representative classes in the study area with the thermal patterns reported in low- and mid-latitude cities. In general, this study represents the first attempt to use the divisional structure of landscapes in Local Climate Zones for the understanding of the urban heat island in a small Brazilian tropical city.
\end{abstract}

Keywords: Tropical Climatology. Urban Climatology. Mobile transects.

$\begin{array}{lllll}\text { Caminhos de Geografia } & \text { Uberlândia-MG } & \text { v. 22, n. 79 } & \text { Fev/2021 } & \text { p. 161-179 Página } 161\end{array}$




\section{INTRODUÇÃO}

O modelo de urbanização do Brasil, caracterizado por um crescimento desenfreado de espaços urbanos desprovidos de orientações em sua produção, culminou na redução da resiliência das cidades e na definição de áreas com elevada vulnerabilidade (natural e social). Apesar da desaceleração nos últimos anos, a Organização das Nações Unidas - ONU (2019) estimou um aumento da taxa de urbanização do país de $87 \%$ para $92 \%$ no período 2018 - 2050.

A relação desse perfil de urbanização com as mudanças climáticas em curso na escala global (PAINEL INTERGOVERNAMENTAL SOBRE MUDANÇAS CLIMÁTICAS - IPCC, 2015) configura um quadro de preocupações acerca dos problemas ambientais das cidades brasileiras oriundos das perturbações do clima (SATTERTHWAITE et al., 2007; RIBEIRO, 2008; BALK et al., 2009; MENDONÇA, 2010; IPCC, 2014; PAINEL BRASILEIRO DE MUDANÇAS CLIMÁTICAS - PBMC, 2014, 2016).

Assim como em outros países altamente urbanizados, as modificações impostas nos componentes do sistema climático local pelo padrão das cidades do país expõem a população às implicações (estresse térmico, comprometimento da qualidade do ar, aumento no consumo de energia e redefinição do planejamento urbano) das ilhas de calor urbanas (ICUs), as quais podem ser acentuadas pelas mudanças climáticas globais (VOOGT, 2002; CORBURN, 2009; IPCC, 2014).

Nessa perspectiva, Huang et al. (2019) apresentaram as projeções mundiais de intensificação das ICUs até 2050 segundo as tendências contínuas de expansão das áreas urbanas e das mudanças climáticas induzidas por um cenário de emissão média de gases de efeito estufa (GEE), constante no último relatório do IPCC. De acordo com os autores, espera-se que as cidades tropicais, especialmente aquelas do Hemisfério Sul, experimentem um aquecimento médio de $0,2^{\circ} \mathrm{C}$ a $0,3^{\circ} \mathrm{C}$, podendo ultrapassar o valor de $1^{\circ} \mathrm{C}$.

No Brasil, o quadro de referência teórico-metodológico para o estudo das ICUs sob a perspectiva geográfica remonta ao Sistema Clima Urbano (SCU) de Monteiro (1976), cujo paradigma se mantém atual no âmbito da Climatologia Urbana brasileira em razão de sua abertura para aperfeiçoamentos consoantes com os avanços científicos e tecnológicos mais recentes vinculados à temática.

Na fundamentação do SCU, Monteiro (1976) considera a ICU como o principal produto do subsistema termodinâmico, o qual possui no núcleo de sua estrutura a demanda por informações sobre o uso da terra, a morfologia urbana e as suas funções para respaldar a compreensão dos processos de transformação e produção de energia que configuram o fenômeno. A distinção desses componentes na organização interna do modelo converge às premissas do sistema de classificação das Zonas Climáticas Locais (LCZs, na sigla em inglês) desenvolvido por Stewart (2011) e amplamente difundido em Stewart e Oke (2012).

O sistema LCZ foi concebido para atender dois propósitos específicos, sendo esses: 1) padronizar a documentação dos metadados do local de mensuração das ICUs a fim de favorecer a comparação dos contrastes térmicos das combinações de paisagens no intraurbano e entre cidades e; 2) fornecer um novo preceito para a quantificação das intensidades das ICUs (STEWART e OKE, 2012). O desenvolvimento desses pressupostos tem promovido avanços na comunicação e no refinamento de aspectos metodológicos dos estudos das ICUs.

Em relação à primeira contribuição, o esquema LCZ facilita a comparação dos resultados por compreender que cada classe possui um regime próprio da temperatura do ar derivado da combinação exclusiva de um conjunto completo de propriedades físicas da superfície (estrutura, cobertura, material e metabolismo). No âmbito da contribuição metodológica, a abordagem das LCZs viabiliza uma expressão consistente para mensurar as intensidades das ICUs, a qual ainda institui uma representação mais ampla do fenômeno e de sua magnitude diante da definição tradicional. Nesse contexto, a medida da intensidade da ICU deixa de ser operacionalizada pela dicotomia urbano - rural $\left(\Delta T_{u}-r\right)$, e passa a ser baseada nas diferenças de temperatura entre as classes LCZs $(\Delta \mathrm{T} L C Z X-Y)$.

Embora o sistema de classificação LCZ não tenha sido inicialmente projetado para o mapeamento completo das cidades, esse procedimento se mostra promissor à compartimentação das áreas urbanas em paisagens distintas no campo termodinâmico pela combinação de propriedades físicas da superfície local. Recentemente, a busca pela adequação do sistema LCZ para fins de mapeamento resultou na sistematização de diversas propostas metodológicas (automáticas e semiautomáticas) para a produção de mapas padronizados de distintas cidades ao redor do mundo (BECHTEL e DANEKE, 2012; ALEXANDER e MILLS, 2014; LELOVICS et al., 2014; UNGER; LELOVICS; GÁL, 2014; BECHTEL et al., 2015; LECONTE et al., 2015; 2017; CHIEPPA; BUSH; MITRA, 2018; HIDALGO et al., 2019; QIU et al., 2019; REN et al., 2019). 
A revisão da literatura da Climatologia Urbana brasileira evidencia um quadro de subutilização do sistema LCZ como recurso ao estudo das ICUs no cenário nacional, especialmente no emprego dessa abordagem para o mapeamento das áreas urbanas em tipos LCZs. A adoção desse procedimento como estratégia de investigação das ICUs no Brasil restringe-se às pesquisas conduzidas em cidades de médio porte (CARDOSO e AMORIM, 2018; DORIGON, 2019) e em grandes concentrações urbanas (ANJOS, 2017; FERREIRA, 2019; FERREIRA e UGEDA JÚNIOR, 2020). Assim, admite-se a necessidade de verificar a aplicabilidade dessa proposta teórica-metodológica em centros urbanos menores do país.

Diante dessa conjuntura, o presente estudo teve como objetivo avaliar as intensidades do fenômeno da ICU em cidade de pequeno porte com base nos princípios do sistema LCZ. Essa avaliação foi realizada por meio do uso de dados da temperatura do ar obtidos na execução de transectos móveis na cidade de Sacramento (MG) em episódios representativos da primavera.

\section{MATERIAL E MÉTODO}

\section{Área de estudo}

A cidade de Sacramento (MG) foi selecionada como área de estudo (Figura 1) em razão do enquadramento de seu perfil urbano no contexto da proposição. De acordo com o censo demográfico de 2010, o município contava com 23.896 habitantes, sendo 19.275 residentes em áreas urbanas, os quais representavam 80,7\% da população absoluta (INSTITUTO BRASILEIRO DE GEOGRAFIA E ESTATÍSTICA - IBGE, 2011). Ao considerar a rede urbana como principal elemento de referência, a área de estudo integra a Região Imediata de Uberaba (MG), que é composta por 10 municípios no total (IBGE, 2017).

O sítio urbano de Sacramento (MG) possui relevo predominantemente ondulado, com variação altimétrica de $799 \mathrm{~m}$ a $1.008 \mathrm{~m}$. A sua paisagem está configurada em área do Bioma Cerrado, sustentando formações florestais, savânicas e campestres (PROJETO MAPBIOMAS, 2020). No que tange aos aspectos climáticos, a área de estudo é caracterizada pelo tipo Aw (DUBREUIL et al., 2018), e compreende os climas regionais tropicais alternadamente secos e úmidos, que são controlados por massas equatoriais e tropicais (MONTEIRO, 1973).

Figura 1 - Sacramento (MG): localização da área de estudo no contexto nacional e regional.

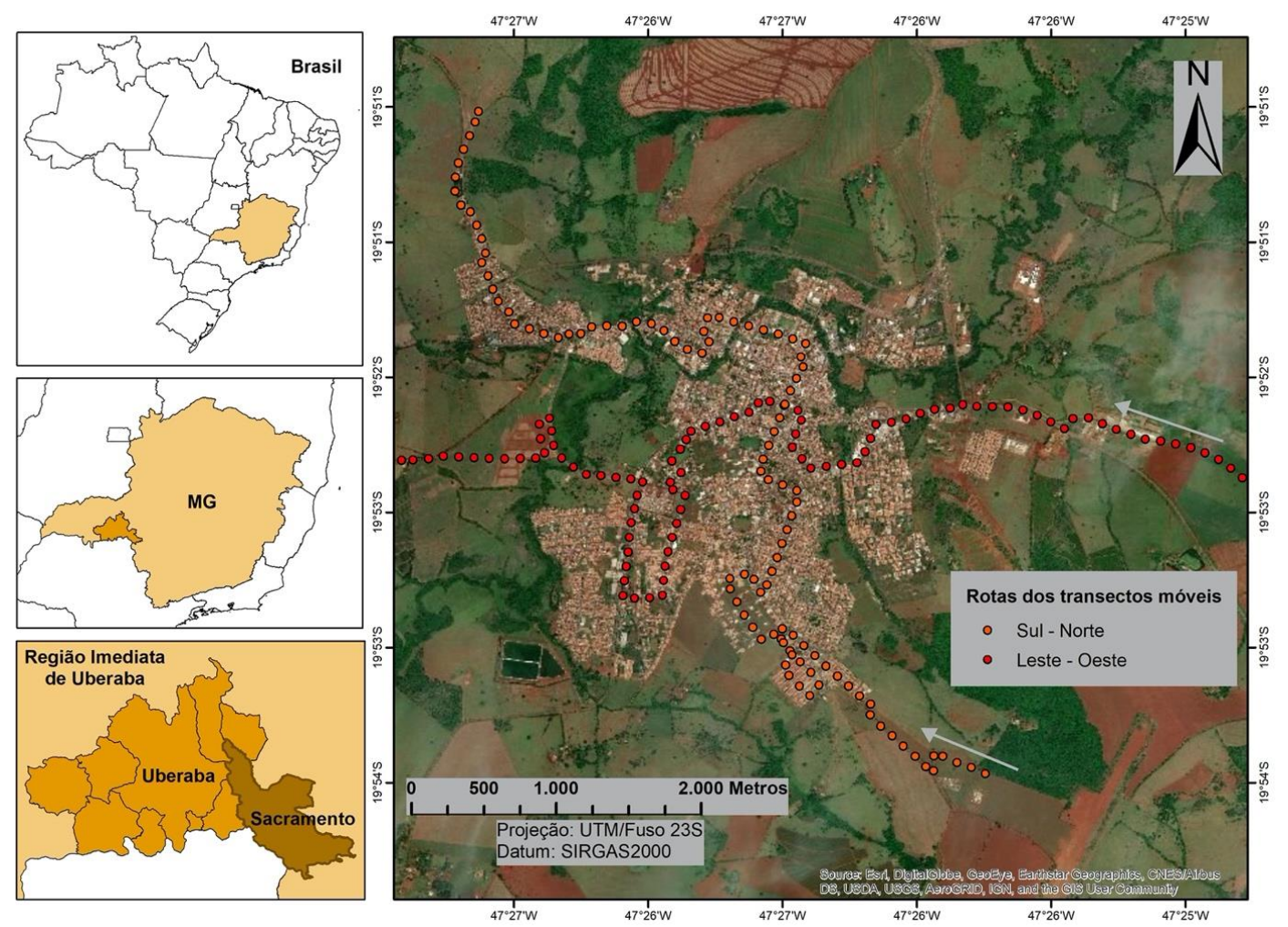

Fonte: Elaborado pelos autores (2020). 


\section{METODOLOGIA}

A fundamentação teórico-metodológica do estudo foi embasada nos princípios do SCU de Monteiro (1976), sendo a investigação do fenômeno da ICU da referida cidade amparada pelo referencial do subsistema termodinâmico. Esse subsistema compreende o nível elementar do SCU, pois permeia toda a sua estrutura e desempenha um papel fundamental na produção do balanço de energia líquida atuante no sistema.

A avaliação do produto desse subsistema em Sacramento (MG) foi realizada com base na articulação entre os dados obtidos na escala local (medidas móveis da temperatura do ar e metadados das LCZs) e aqueles representativos da dinâmica atmosférica do ambiente regional, de modo que fosse possível compreender as respostas dos condicionantes urbanos ao ritmo climático.

\section{O sistema de classificação das LCZs e a sua tipologia conceitual de magnitude da ICU}

As LCZs foram definidas formalmente por Stewart e Oke (2012, p. 1884) como "áreas de uniforme cobertura superficial, estrutura, material e atividades antropogênicas que abrangem centenas de metros até vários quilômetros em escala horizontal". A concepção do sistema de classificação das LCZs é fundamentada na divisão da paisagem de acordo com a influência de propriedades da estrutura (altura e espaçamento das edificações e das espécies arbóreas) e da cobertura da superfície (permeável ou impermeável) no campo termodinâmico.

A combinação das propriedades culminou na composição de um conjunto padrão de 17 classes LCZs (Figura 2), que são agrupadas em duas séries principais: tipos edificados $(1-10)$ e tipos de cobertura da terra $(A-G)$. Caso o estudo abarque uma classificação de curto intervalo temporal, as notações da última série podem conter referências de propriedades sazonais ou efêmeras $(b-w)$. Para atender às particularidades de cada pesquisa, o sistema ainda permite uma subclassificação por meio da associação entre as classes das referidas séries (Figura 3).

Figura 2 - Sistema de classificação LCZ.
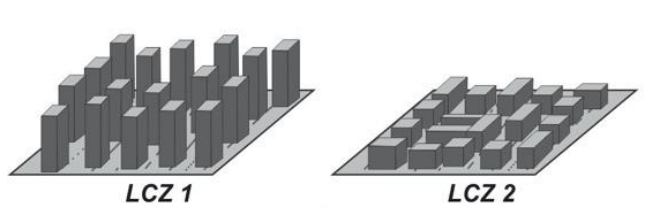

Tipos edificados

Compacta de alta elevação Compacta de média elevação Compacta de baixa elevação
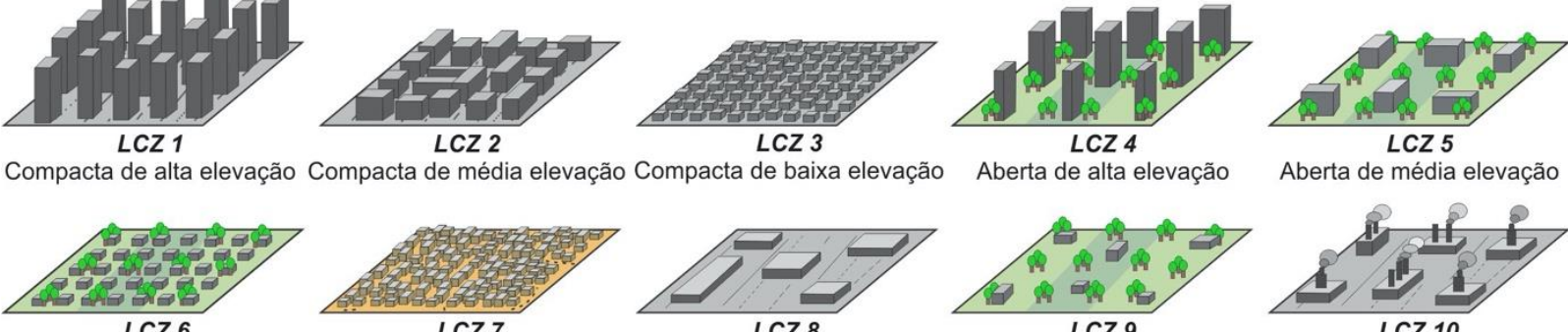

LCZ 6
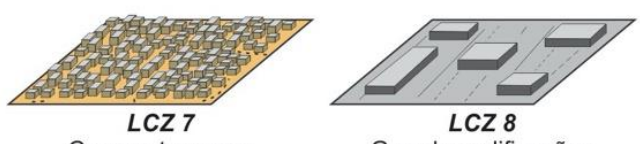

\section{Aberta de alta elevação}

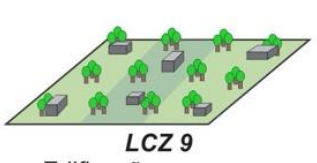

Edificações esparsas
Aberta de média elevação

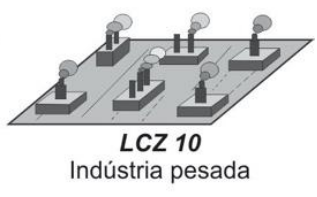

Tipos de cobertura da terra

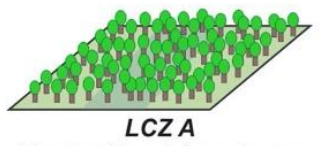

Veza

Vegetação arbórea densa

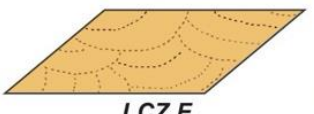

Solo exposto ou areia

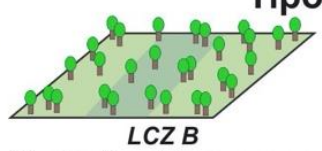

Vegetação arbórea esparsa

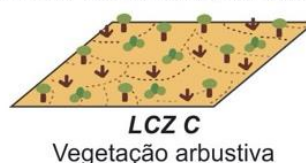

Vegetação arbustiva

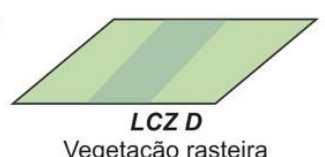

Vegetação rasteira

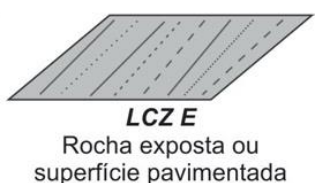

Propriedades variáveis da cobertura da terra

b. árvores sem folhas s. cobertura de neve $\quad d$. solo seco $\quad$ w. solo úmido

Fonte: Adaptado de STEWART e OKE (2012, tradução nossa). 
Figura 3 - Subclasses: convenção e exemplos de combinações de tipos LCZs

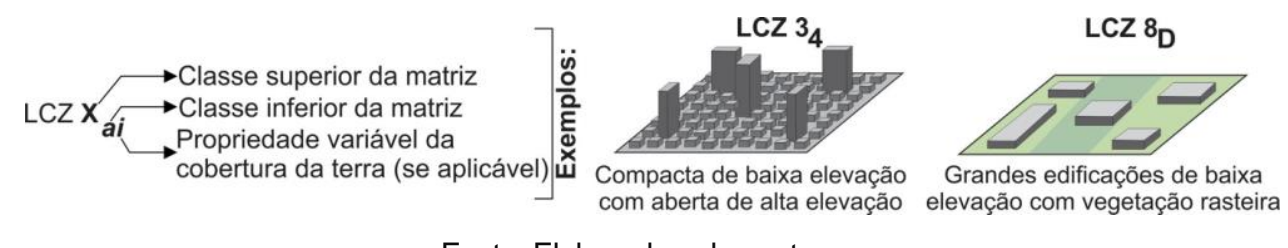

Fonte: Elaborado pelos autores.

Apesar da instituição de subclasses LCZs favorecer a descrição física de uma paisagem, Stewart e Oke (2012) realizaram as seguintes ressalvas quanto ao seu uso diante dos propósitos do sistema: (i) o comprometimento da comunicação e/ou comparação das paisagens de distintos estudos; (ii) a dificuldade de reconhecer previamente o seu comportamento termal em razão da inexistência de propriedades físicas pré-definidas no sistema e; (iii) a relativização do contraste térmico com as LCZs de sua notação, pois as diferenças térmicas entre LCZs sucessivas no conjunto padrão não ultrapassam $1-2^{\circ} \mathrm{C}$. Assim, as subclasses devem ser utilizadas em situações imprescindíveis segundo as características das paisagens da área de estudo.

O campo térmico das LCZs é espacialmente contínuo, ou seja, a condição do ar (e suas propriedades) de uma classe se funde de modo gradual com aquela existente nos limites das LCZs circunvizinhas, formando áreas de transição térmica pela advecção. Deste modo, os referidos autores afirmam que cada LCZ deve ter um diâmetro mínimo de 400 a 1.000 m (correspondentes a um raio de 200 a 500 m, respectivamente) para que a porção do ar de sua camada superficial fique inteiramente no seu interior $\mathrm{e}$ não se sobreponha às LCZs adjacentes com distintas estruturas ou coberturas da terra.

O processo de classificação e mapeamento das LCZs do sítio urbano de Sacramento (MG) foi executado com base na adaptação de diretrizes de Stewart (2011) e na sistematização para decompor a malha urbana em tipos LCZs de Cardoso e Amorim (2018). Assim, as seguintes etapas foram delineadas para efetivar esse procedimento: (i) reconhecimento da diversidade paisagística da cidade e coleta de metadados de suas LCZs e; (ii) classificação e mapeamento das LCZs. Para a obtenção de resultados mais precisos nessas etapas, deve-se atentar ao uso da escala local como premissa do esquema LCZ.

O desenvolvimento da etapa (i) envolveu trabalhos de campo e a análise de imagens de satélite da base de dados Esri World Imagery do software ArcGIS ${ }^{\odot}$ 10.6. Os dados extraídos dessas fontes possibilitaram a estruturação de fichas padronizadas para cada uma das LCZs identificadas na área de estudo conforme o layout gráfico de Stewart (2011). Na presente proposição, tais fichas de dados contemplavam as definições, ilustrações e gráficos de barras das propriedades físicas vinculadas à cobertura da superfície de cada LCZ.

É importante salientar que os metadados das propriedades da cobertura da superfície das LCZs (proporção da área construída em \% - $\lambda_{b}$; proporção impermeável da superfície em \% - $\lambda_{i}$ e; proporção permeável da superfície em \% - $\lambda_{v}$ ) foram adquiridos na avaliação de amostras circulares contendo a dimensão mínima (diâmetro de 400 m) exigida no esquema de Stewart (2011).

Embora as implicações relacionadas ao processo de subclassificação tenham sido consideradas durante a realização da etapa (i), houve a necessidade do uso de subclasses para caracterizar o universo paisagístico de Sacramento (MG). Dentre elas, destacam-se a LCZ 3в (compacta de baixa elevação com vegetação arbórea esparsa) e a LCZ 3D (compacta de baixa elevação com vegetação rasteira).

As peculiaridades atreladas à localização do sítio urbano de Sacramento (MG) em área do Bioma Cerrado, associadas com o típico padrão construtivo derivado de expansão da malha urbana desprovida de orientações na produção do espaço, resultou na configuração de setores com heterogeneidade paisagística. Assim, a área de estudo é composta por alguns lotes com edificações compactas organizadas no entorno de fragmentos de mata ripária, formação natural campestre ou de glebas às atividades agrícolas.

Em consonância com a proposta de Cardoso e Amorim (2018), a etapa (ii) foi conduzida por meio da codificação de cada quadra da malha urbana com a sua respectiva classe LCZ segundo a análise de imagens de satélite de alta resolução da base de dados Esri World Imagery do módulo ArcMap do ArcGIS ${ }^{\odot} 10.6$.

As fichas de dados das LCZs da área de estudo forneceram maior objetividade na definição das correspondências entre as paisagens das quadras e as classes LCZs. As dificuldades encontradas 
durante o processo de classificação foram superadas com o auxílio do guia prático de Stewart (2018), que exprime uma sequência lógica de etapas com perguntas e exercícios cognitivos voltados à identificação das LCZs em áreas com relativo grau de incerteza.

Além de contribuir para a padronização da comunicação nas investigações da Climatologia Urbana, o sistema de classificação das LCZs possui como finalidade primordial o fornecimento de um novo protocolo para mensurar as intensidades do efeito das ICUs em qualquer cidade.

Diferentemente das abordagens tradicionais baseadas na expressão $\Delta T_{u-r}$, a quantificação da intensidade das ICUs é dada pela diferença de temperatura entre as LCZs ( $\Delta$ TLCZX $-Y$ ). A aplicação desse preceito do sistema LCZ fornece maior significado às análises das intensidades das ICUs entre cidades e dos contrastes térmicos no espaço intraurbano, pois viabiliza explicações fundamentadas nas relações da temperatura com a morfologia e o material da superfície.

Assim, a ICU não é retratada como uma entidade singular de única magnitude, e sim como um fenômeno composto por partes locais com magnitudes que variam conforme as distintas possibilidades de combinações existentes entre as LCZs da área de estudo (STEWART, 2011).

No âmbito desse quadro conceitual proposto por Stewart (2011) para a distinção das magnitudes das ICUs, as diferenças de temperatura entre as LCZs podem ser enquadradas nas seguintes categorias: pequena $\left(<2^{\circ} \mathrm{C}\right)$, média $\left(2-5^{\circ} \mathrm{C}\right)$ ou grande $\left(>5^{\circ} \mathrm{C}\right)$. A figura 4 representa a concepção das referidas categorias de magnitude das ICUs como resposta às diferenças na morfologia e no material de superfície das LCZs. As extremidades do gráfico que compõem a figura 4 envolvem alguns exemplos de cenários possíveis de relações entre a morfologia e o material de superfície das LCZs e as suas respectivas magnitudes da ICU.

Figura 4 - Tipologia conceitual das categorias de magnitude das ICUs com base no $\Delta$ TLCZ.

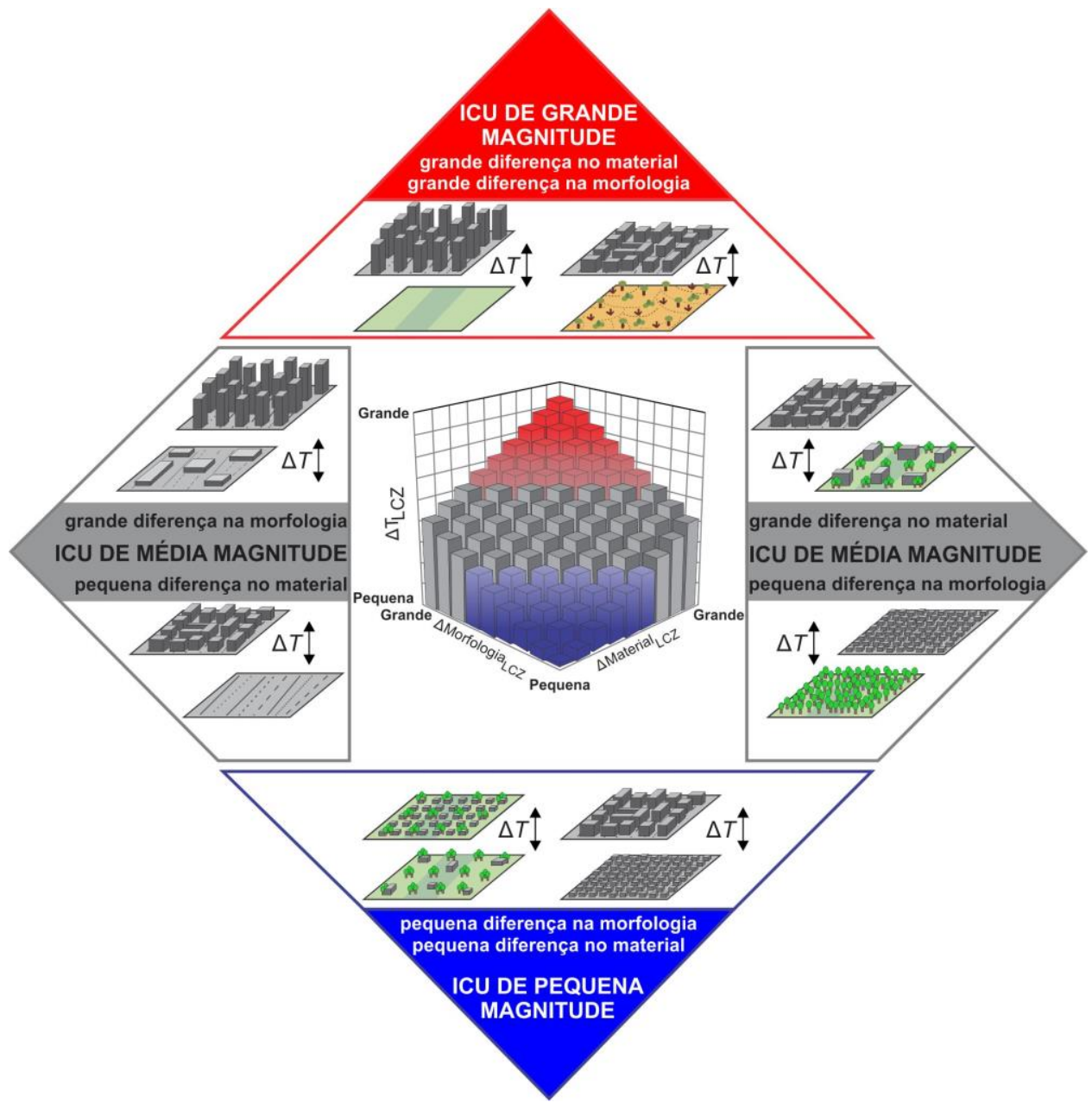

Fonte: Adaptado de STEWART (2011, tradução nossa).

Caminhos de Geografia $\quad$ Uberlândia-MG $\quad$ v. 22, n. 79 $\quad$ Fev/2021 $\quad$ p. 161-179 Página 166


Stewart (2011) ressalta que a validação dessa tipologia da magnitude da ICU pressupõe o controle de condicionantes não urbanos externos às propriedades das LCZs (por exemplo, as variáveis geomorfométricas) durante as análises da temperatura, pois eles podem comprometer a leitura do efetivo papel desempenhado pelo urbano na definição da magnitude da ICU.

Com o intuito de atender essa recomendação, foram considerados os valores de temperatura registrados nas amostras circulares das LCZs mais expressivas da área de estudo localizadas em setores com características similares em relação aos seus aspectos geomorfométricos (hipsometria, orientação das vertentes, sombreamento do relevo e declividade). Assim, a definição das magnitudes da ICU de Sacramento (MG) compreendeu as diferenças térmicas entre as seguintes classes LCZs: compacta de baixa elevação (LCZ 3), compacta de baixa elevação com vegetação rasteira (LCZ 3D), compacta pouco consolidada de baixa elevação (LCZ 7), grandes edificações de baixa elevação com vegetação rasteira (LCZ 8D) e vegetação rasteira (LCZ D).

Os dados de temperatura dos pontos de amostragem dos transectos móveis inseridos no interior das amostras circulares das LCZs selecionadas foram tratados para a geração de recursos gráficos derivados de uma estatística descritiva da diferenciação térmica de cada classe LCZ e de suas respectivas magnitudes ao longo dos episódios, seguindo a estrutura das representações de estudos baseados no esquema LCZ (STEWART, 2011; STEWART e OKE, 2012; STEWART; OKE; KRAYENHOFF, 2014; CARDOSO e AMORIM, 2018).

\section{TRANSECTOS MÓVEIS}

A abordagem dos transectos móveis foi adotada na presente proposição em razão de sua ampla utilização nas mais distintas áreas de estudo (CHANDLER, 1962; 1965; HUTCHEON et al., 1967; KOPEC, 1970; OKE, 1973; OKE e MAXWELL, 1975; BRAZEL e JOHNSON, 1980; YAMASHITA, 1996; SPRONKENSMITH e OKE, 1998; STEWART, 2000; ALONSO; LABAJO; FIDALGO, 2003; HEDQUIST e BRAZEL, 2006; AMORIM et al., 2009; SUN et al., 2009) e de seu baixo custo operacional (GARTLAND, 2010; PORANGABA; TEIXEIRA; AMORIM, 2017). A técnica consiste no registro da temperatura do ar ao longo de trajeto predeterminado que cubra locais representativos da paisagem urbana.

Em consonância com o padrão ideal de condições atmosféricas usualmente adotado para a determinação da intensidade das ICUs (OKE e MAXWELL, 1975; OKE, 2006; AMORIM et al., 2009; GARTLAND, 2010; STEWART, 2011; PORANGABA; TEIXEIRA; AMORIM, 2017), os transectos ocorreram à noite (21h) sob atuação de sistema anticiclônico responsável por estabilidade atmosférica, caracterizada por calmaria (ventos com velocidade $<1,3 \mathrm{~m} / \mathrm{s}$ ) ou ventos fracos (velocidade $<3 \mathrm{~m} / \mathrm{s}$ ), céu sem (ou com poucas) nuvens e ausência de precipitação no período antecedente de 24h às campanhas de campo. Este estudo apresenta 3 episódios da primavera (15, 16 e 17 de dezembro de 2019) que se enquadram nas referidas condições sinóticas e de tipos de tempo.

A identificação desses episódios foi realizada com base na adoção de princípios do plano metodológico da análise rítmica de Monteiro (1971), envolvendo o monitoramento dos sistemas atmosféricos regionais segundo a apreciação conjunta de cartas sinóticas de superfície da Marinha do Brasil e do Centro de Previsão de Tempo e Estudos Climáticos (CPTEC) do Instituto Nacional de Pesquisas Espaciais (INPE), imagens dos canais 09 e 13 do satélite Goes 16 da Divisão de Satélites e Sistemas Ambientais (DAS) do CPTEC/INPE e, ainda, os dados de elementos climáticos da estação meteorológica de superfície automática do município (estação do INMET - A525, Código OMM 86795).

O cuidado com o controle associado aos sistemas atmosféricos atuantes e os tipos de tempo garantiu (1) a maximização dos contrastes térmicos ao longo das rotas dos transectos e, consequentemente, entre as principais LCZs da área de estudo e; (2) a minimização da transferência via advecção do efeito das propriedades térmicas e de umidade de uma classe LCZ sobre os limites das demais identificadas na área de estudo.

As rotas dos transectos longitudinal $(10,2 \mathrm{~km})$ e latitudinal $(9,2 \mathrm{~km})$ foram estabelecidas com o intuito de atravessar os setores centrais das LCZs em distintos arranjos de variáveis geomorfométricas (hipsometria, orientação das vertentes, sombreamento do relevo e declividade) do sítio urbano de Sacramento (MG). Durante os trabalhos de campo, um único veículo, conduzido com velocidade máxima de $30 \mathrm{~km} / \mathrm{h}$, percorria ambas as rotas em aproximadamente $1 \mathrm{~h}$.

Para cada um dos episódios selecionados neste estudo, os registros da temperatura do ar ocorreram de modo preciso nos locais definidos ao longo das rotas em intervalos regulares de $100 \mathrm{~m}$, totalizando 104 
pontos de coleta no percurso sul-norte e 93 no leste-oeste. O rigor das mensurações nos mesmos locais de coleta durante as campanhas de campo foi alcançado pelo uso do aplicativo móvel (App) de mapas offline Avenza Maps $^{\circledR}$, contendo as rotas dos transectos e os seus respectivos pontos de coleta no intervalo de interesse sobre uma imagem de satélite da área de estudo (Figura $5 \mathrm{~A}$ ).

A base de dados importada no App foi construída no módulo ArcMap do software ArcGIS ${ }^{\odot}$ 10.6. Cada rota foi vetorizada por meio da ferramenta de construção de feições do tipo polyline e os locais de amostragem definidos automaticamente pela função Construct Points da ferramenta de edição, que permite a criação de pontos equidistantes na unidade de medida do mapa. Posteriormente, esses arquivos vetoriais foram exportados para o formato Keyhole Markup Language (KML), que é uma linguagem suportada para importação no App na forma de camadas passíveis de edição.

Em relação à imagem de satélite utilizada como referência para a navegação em campo com o App, essa foi exportada da base de dados Esri World Imagery do referido software no formato GeoPDF.

Após vincular os vetores à imagem geoespacial no ambiente do App, o Sistema de Posicionamento Global (GPS) interno do smartphone permitiu o rastreamento da localização precisa do automóvel perpassando pelos locais de coleta de dados ao longo das rotas. Os registros dos valores da temperatura do ar foram realizados manualmente por membro da equipe de coleta de dados nos instantes da navegação que o automóvel se encontrava ao centro dos marcadores dos locais de amostragem (Figura 5B). Ressalta-se ainda que o uso do App evitou a necessidade de memorização dos percursos pelo motorista.

Figura 5 - Interfaces do Avenza Maps ${ }^{\circledR}$. A. Rotas dos transectos e pontos de amostragem da toํ $\mathrm{C}$ do ar em Sacramento (MG); B. Navegação e instante exato do registro da toำ do ar.
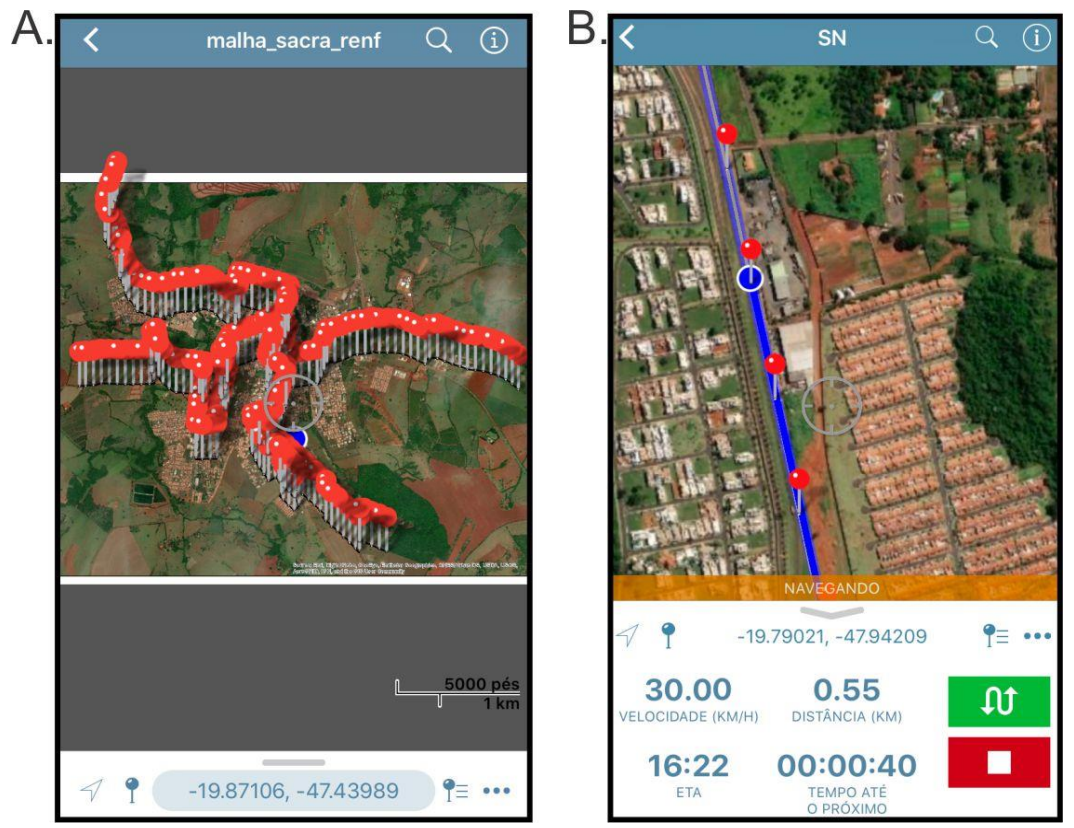

Fonte: Elaborado pelos autores.

Diante do exposto, admite-se que o gerenciamento dos transectos via uso do referido App contribuiu para a maior precisão dos registros em campo, amenizando as desvantagens reportadas em estudos (FIALHO, 2009; AMORIM, 2017) que abordam os procedimentos metodológicos das medidas móveis.

As mensurações da temperatura do ar foram realizadas por meio de termo-higrômetro digital (modelo 7664.01.0.00 com acurácia de $\pm 0,1^{\circ} \mathrm{C}$ ), que foi acoplado na janela ao lado do passageiro em aparato estruturado com material de Policloreto de Vinila - PVC (Figura 6A) segundo adaptações do modelo apresentado por Makido et al. (2016) e Voelkel e Shandas (2017). Com base nesse aparato, o sensor ficou posicionado $60 \mathrm{~cm}$ acima do teto do veículo e $2 \mathrm{~m}$ da superfície (Figura 6B). Por fim, evidencia-se a concessão de tempo suficiente ( $5 \mathrm{~min}$ ) à estabilização do sensor antes do início de cada rota em razão de sua exposição ao ar livre.

$\begin{array}{lllll}\text { Caminhos de Geografia } & \text { Uberlândia-MG } & \text { v. 22, n. } 79 & \text { Fev/2021 } & \text { p. 161-179 Página } 168\end{array}$


Figura 6 - Detalhes técnicos dos recursos utilizados nas campanhas de campo. A. Modelo da estrutura que sustenta o sensor; B. Modelo acoplado ao veículo.
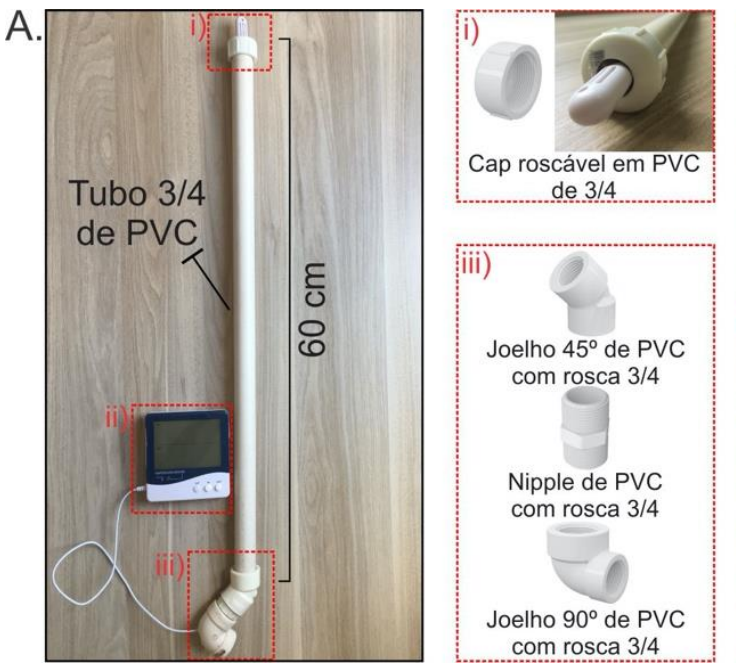
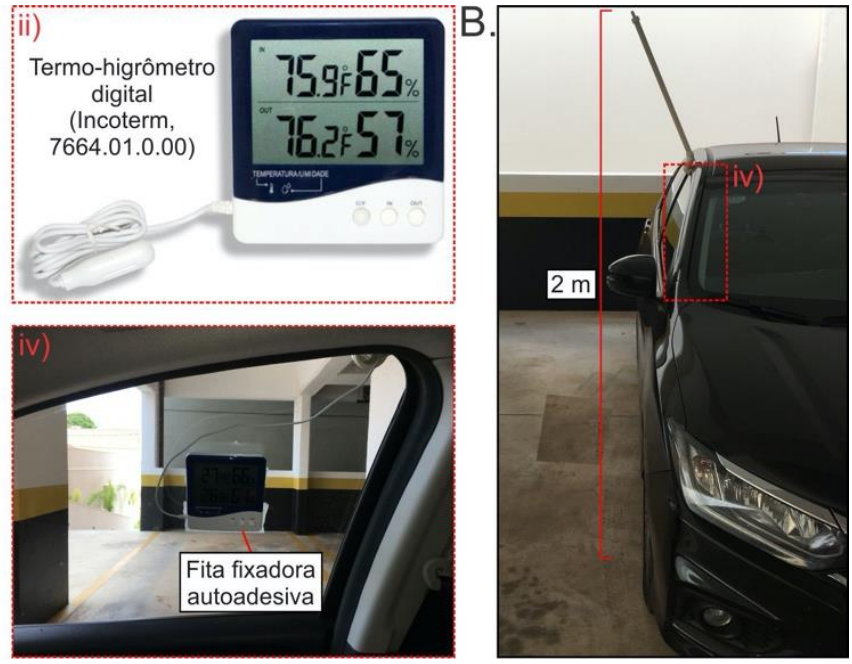

Fonte: Elaborado pelos autores.

\section{RESULTADOS E DISCUSSÃO}

\section{LCZs do sítio urbano de Sacramento (MG)}

A análise do mapa das LCZs de Sacramento (MG) revela a disposição espacial das paisagens de sua malha urbana e circunvizinhança (Figura 7), exclusivamente compostas pelas seguintes classes LCZs: 3 , 3B, 3D, 7, 8, 8D, 10, A, B, D, E e G. No âmbito das tipologias edificadas, a área de estudo é predominantemente constituída pela LCZ 3 (centro e bairros antigos no setor sul, sudoeste e noroeste) e manchas relevantes da LCZ $3_{\mathrm{B}}$ em bairros suburbanos. Ressalta-se ainda a existência da LCZ 7 em bairro periférico do extremo sul da cidade. Em relação aos tipos de cobertura da terra, destaca-se a LCZ D, que abarca quadras na periferia (setores sudeste e oeste) e extensas áreas no periurbano, associadas, respectivamente, aos loteamentos residenciais para a população de maior poder aquisitivo e aos terrenos tipicamente rurais cobertos por formação natural campestre (campo limpo) ou espécies agrícolas (pasto limpo ou cana-de-açúcar).

Figura 7 - Sacramento (MG): mapa das LCZs da malha urbana e circunvizinhança, 2020.

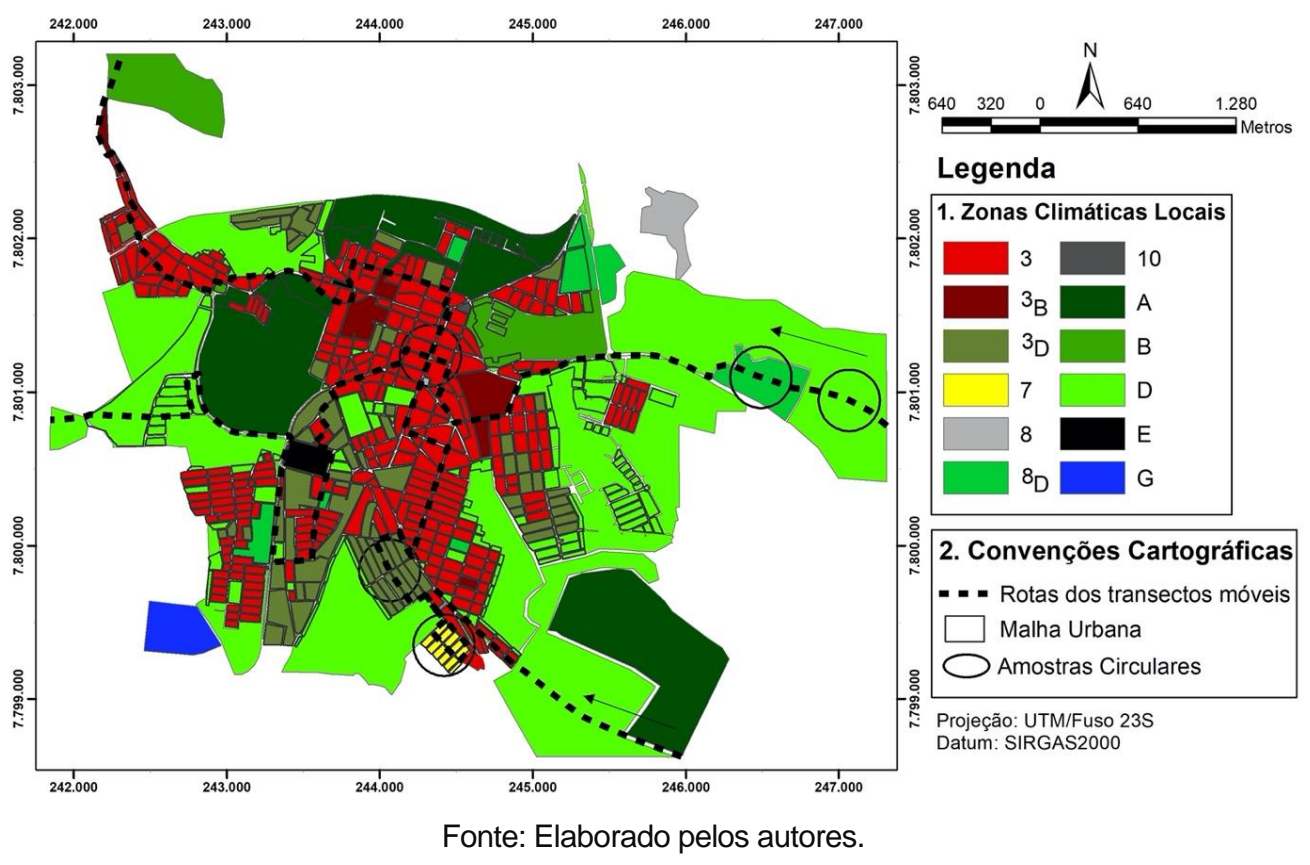


Com exceção da inexistência dos tipos edificados de média e alta elevação, comumente identificados no arranjo dos grandes centros urbanos brasileiros, a configuração verificada no mapa das LCZs de Sacramento (MG) reproduz a típica estrutura morfológica das cidades do país, que é caracterizada por (i) uma zona central antiga de elevada densidade construtiva, com predomínio de materiais de construção pesados, cobertura da terra essencialmente pavimentada, poucas ou nenhuma árvore, maior fluxo de tráfego e, destinada às funções comercial e residencial; (ii) bairros suburbanos consolidados com as referidas forma e funções, constituindo-se em subcentros da cidade e; (iii) bairros periféricos pouco consolidados de moradia popular e/ou espaços residenciais dotados de infraestrutura em razão da especulação imobiliária para atender as classes média-alta.

Esse perfil foi delineado pelas transformações recentes nas relações entre os distintos níveis de cidades do país, que acarretaram na transposição do crescimento horizontal rápido e desorganizado das cidades de maior porte àquelas de menor em razão da intensificação das interações entre tais centros urbanos (IBGE, 2016; 2017).

Em relação ao processo de mapeamento das LCZs adotado neste estudo, os resultados obtidos demonstraram o seu elevado potencial de aplicabilidade para cidades de pequeno porte, em consonância com o nível escalar que fundamenta o sistema LCZ. Ademais, admite-se que o maior nível de detalhe do produto cartográfico final possibilitou a identificação de lotes individualizados no interior de extensas áreas homogêneas de algumas LCZs. Esse maior refinamento impede o risco de superestimar a distribuição espacial de LCZs dos tipos edificados conforme reportado em estudos sobre as propostas metodológicas de mapeamento das LCZs (LELOVICS et al., 2014; BECHTEL et al., 2015; HIDALGO et al. 2019) e, ainda, fornece subsídios para o desenvolvimento de estudos microclimáticos no contexto da malha urbana da cidade.

No que tange aos metadados das LCZs selecionadas nas rotas dos transectos como representativas do sítio urbano de Sacramento/MG (Figura 8), os valores quantificados de propriedades da cobertura da superfície na área total de suas respectivas amostras circulares convergem àqueles estimados por Stewart (2011) às classes LCZs. No caso das subclasses da área de estudo, os valores obtidos compreendem uma mistura das medidas esperadas às classes da matriz LCZ envolvidas na combinação.

Figura 8 - Sacramento (MG): metadados das principais LCZs, 2020.

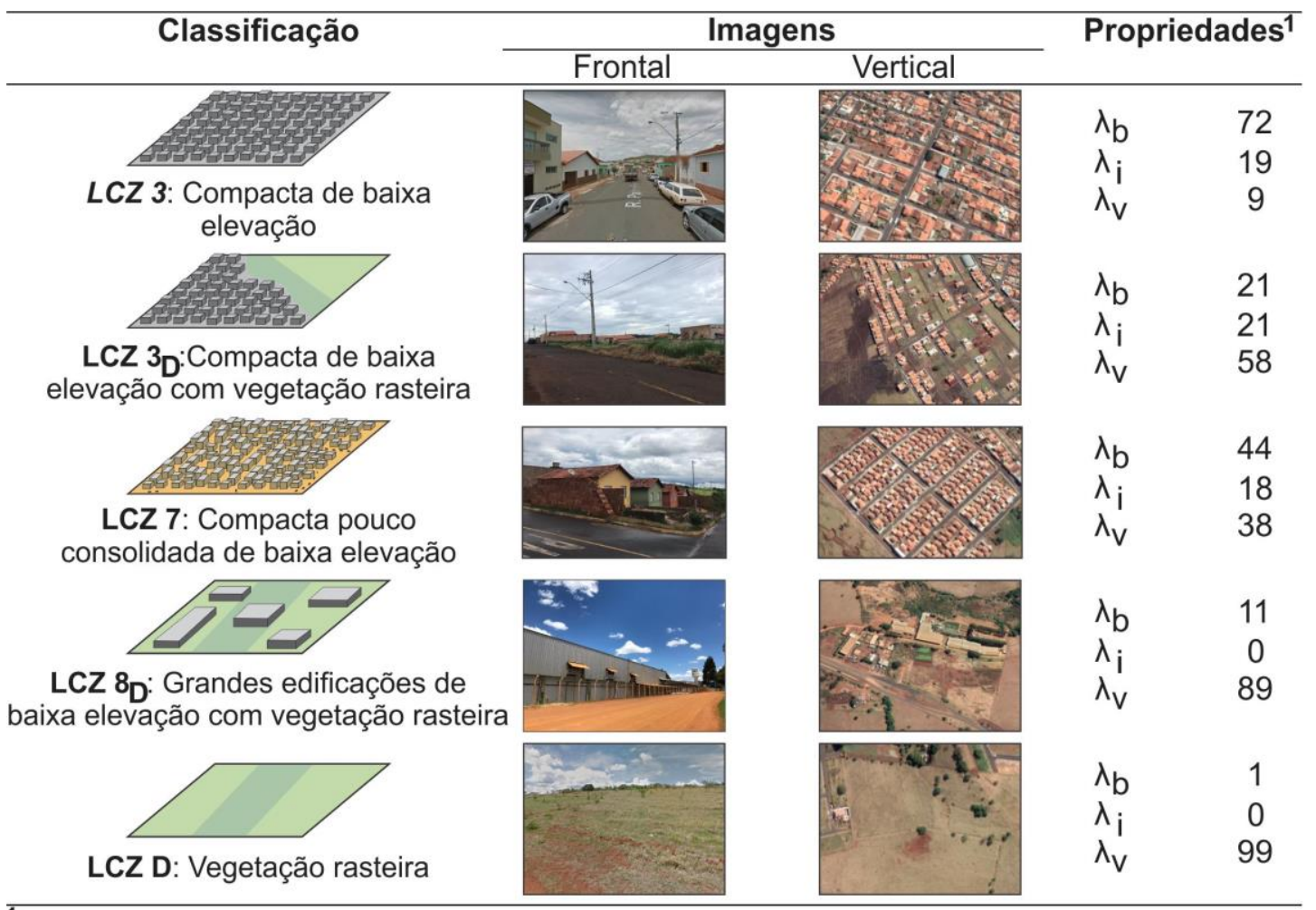

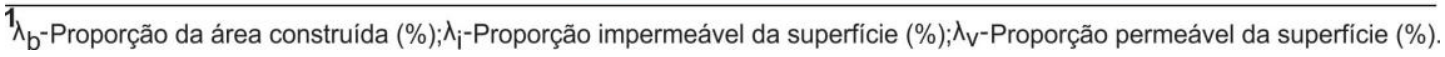

Fonte: Elaborado pelos autores. 
A correspondência entre as medidas quantificadas e as estimadas de metadados das principais LCZs identificadas em Sacramento (MG) valida a seleção dos setores adotados como representativos dos atributos dessas paisagens. Ao considerar ainda a homogeneidade das características geomorfométricas desses locais, admite-se a obtenção de condições efetivas para verificar os efeitos térmicos da estrutura, cobertura superficial, material e atividades antropogênicas na definição das magnitudes da ICU da área de estudo.

\section{Termodinâmica e intensidades das ICUs}

A estabilidade atmosférica durante os 3 episódios da primavera foi causada pela atuação da Massa Tropical Atlântica continentalizada (mTac), que manteve condições favoráveis (Tabela 1) para o desenvolvimento da ICU em Sacramento (MG). Além da velocidade do vento e da quantidade de nuvens registradas em cada noite, destaca-se a diminuição gradativa da umidade relativa durante o período, pois o comportamento desse elemento climático contribuiu significativamente nas respostas diárias dos gradientes térmicos das LCZs selecionadas em relação à temperatura média dos transectos da primavera (Figura 9) e, ainda, às intensidades da ICU formada nessas noites (Figura 10).

Tabela 1 - Dados de elementos climáticos registrados às $21 \mathrm{~h}$ e o sistema atmosférico atuante em cada noite dos transectos móveis, dezembro de 2019.

\begin{tabular}{|c|c|c|c|c|c|c|c|c|}
\hline \multirow[t]{2}{*}{ Data } & \multirow[t]{2}{*}{$\mathrm{t}^{\circ} \mathrm{C}^{1}$} & \multicolumn{2}{|c|}{ Vento $^{1}$} & \multicolumn{2}{|c|}{$\begin{array}{c}\text { Cobertura de } \\
\text { nuvens }^{2}\end{array}$} & \multirow{2}{*}{$\begin{array}{c}\text { Umidade }^{1} \\
(\%)\end{array}$} & \multirow{2}{*}{$\begin{array}{c}\text { Pressão }^{1} \\
\mathrm{hPa}\end{array}$} & \multirow{2}{*}{$\begin{array}{c}\text { Sistema } \\
\text { Atmosférico }\end{array}$} \\
\hline & & $\begin{array}{c}\text { Velocidade } \\
(\mathrm{m} / \mathrm{s})\end{array}$ & Direção $^{3}$ & Oktas & $\begin{array}{c}\text { Código } \\
\text { METAR }^{4}\end{array}$ & & & \\
\hline $15 / 12 / 2019$ & 23,7 & 0,6 & $\mathrm{NE}$ & $3-4$ & Esparsas & 66 & 913 & \\
\hline $16 / 12 / 2019$ & 23,5 & 0,9 & $\mathrm{~N}$ & $1-2$ & Poucas & 57 & 910 & $\mathrm{mTac}$ \\
\hline $17 / 12 / 2019$ & 24,1 & 1,8 & NE & $1-2$ & Poucas & 50 & 910.2 & \\
\hline
\end{tabular}

${ }^{1}$ Estação INMET - A525 (Código OMM 86795); ${ }^{2}$ Aeroporto de Uberaba (MG) - SBUR (IOWA STATE UNIVERSITY ISU, 2020); ${ }^{3}$ Valor angular predominante ao longo do dia; ${ }^{4}$ Tradução nossa.

Fonte: Elaborado pelos autores.

Figura 9 - Sacramento (MG): gráfico da diferenciação térmica das LCZs com base nas temperaturas dos transectos móveis durante noites tranquilas e claras da primavera, dezembro de 2019.
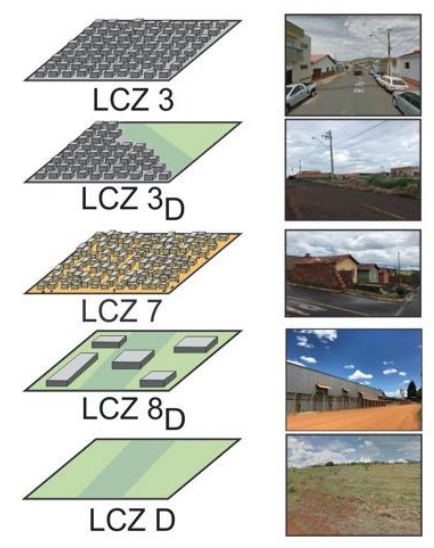

Desvio em relação à temperatura $\left({ }^{\circ} \mathrm{C}\right)$ média dos transectos

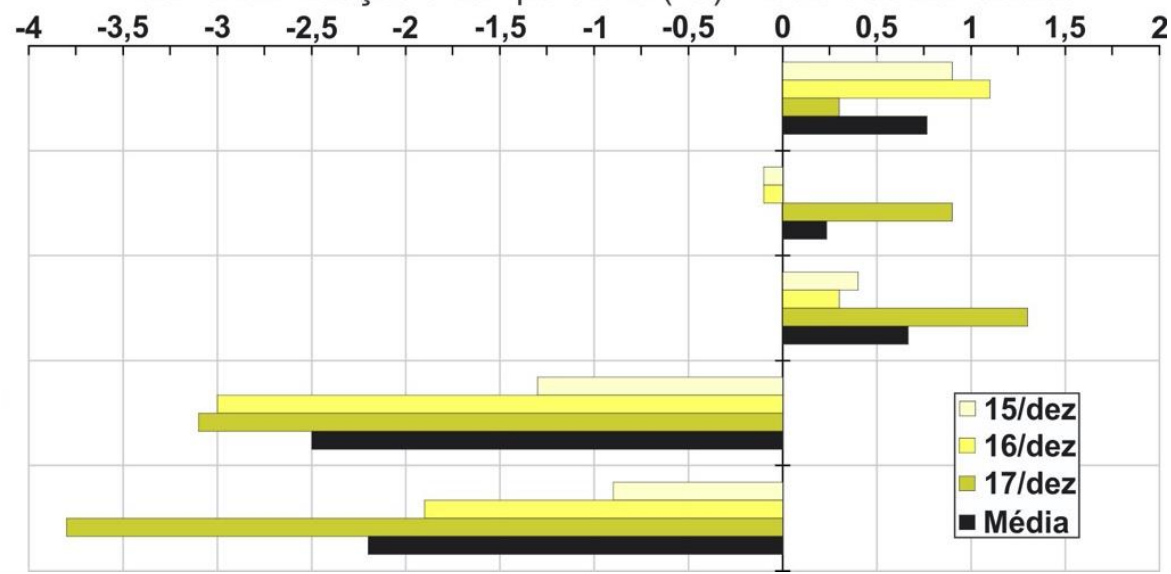

Fonte: Elaborado pelos autores. 
Figura 10 - Sacramento (MG): gráfico da intensidade da ICU ( $\triangle$ TLCZ X-D) durante os transectos móveis noturnos da primavera, dezembro de 2019.

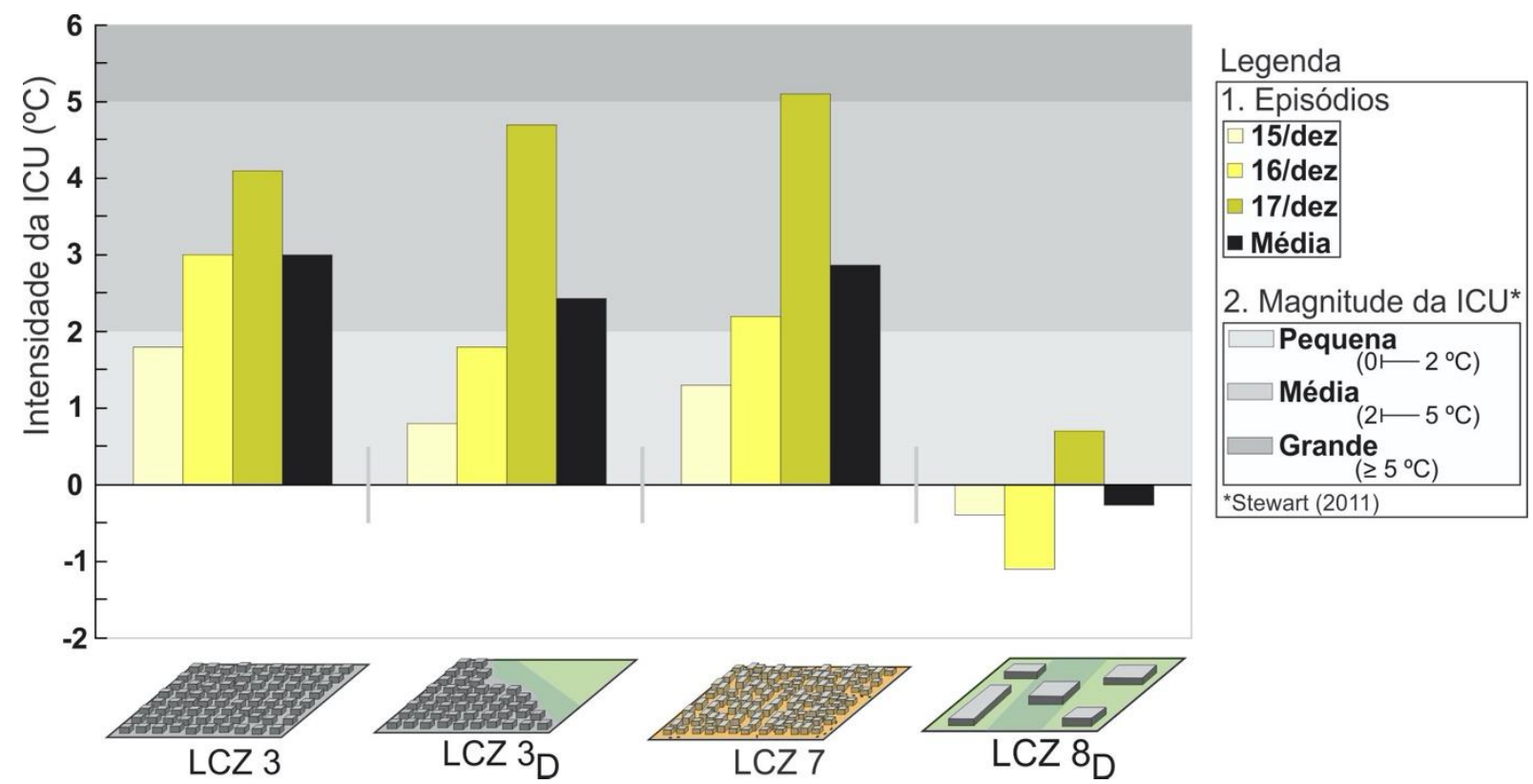

Fonte: Elaborado pelos autores.

No âmbito dos contrastes térmicos das LCZs em relação à temperatura média dos transectos da estação $\left(23,2^{\circ} \mathrm{C}\right)$, a análise da Figura 9 permite a constatação de um padrão geral de temperaturas conduzido pela variação da geometria das edificações e das coberturas de superfície de cada classe LCZ.

As LCZs compostas por elevada densidade de edificações e cobertura essencialmente pavimentada (LCZs 3 e 7) apresentaram desvios positivos durante todos os episódios, enquanto aquelas com arranjo aberto de edificações situadas em terrenos com vegetação rasteira (LCZ 8D) ou com expressiva cobertura permeável (LCD D) foram caracterizadas por anomalias térmicas negativas em todas as noites de coleta de dados. Os dados de temperatura nessas classes LCZs com superfícies predominantemente permeáveis evidenciam o papel da vegetação na dissipação do calor e, ainda, revelam a conformidade do aumento subsequente dos desvios negativos com a variação da umidade. $O$ efeito da vegetação ainda pôde ser verificado na atenuação da influência de propriedades urbanas da LCZ 3D no estabelecimento de seus contrastes térmicos e na definição da alternância de valores positivos e negativos entre os episódios.

A diferença média da temperatura das LCZs urbanas foi de $0,7^{\circ} \mathrm{C}(\operatorname{LCZ} 7)-0,8^{\circ} \mathrm{C}(\mathrm{LCZ} 3)$ acima do valor médio dos transectos da primavera (Figura 9). Em contrapartida, as LCZs constituídas por cobertura uniforme de gramíneas exibiram uma diferença média de $-2,2^{\circ} \mathrm{C}(\mathrm{LCZ} \mathrm{D}),-2,5^{\circ} \mathrm{C}(\mathrm{LCZ} 8 \mathrm{D})$ e $0,2^{\circ} \mathrm{C}(\mathrm{LCZ}$ 3D) durante a estação (Figura 9). A diferenciação térmica interna de cada LCZ nos respectivos episódios da estação também converge para esse padrão, sendo os maiores desvios positivos e negativos registrados no dia 17 de dezembro nas $\operatorname{LCZs} 7\left(1,3^{\circ} \mathrm{C}\right)$ e $\mathrm{D}\left(-3,8^{\circ} \mathrm{C}\right)$.

Outra constatação relevante dessa análise episódica foi a configuração de um decréscimo gradual não linear do conjunto de temperaturas da LCZ 3 para a LCZ D (Figura 9). Essa tendência consistente de redução da temperatura entre as consecutivas LCZs, das classes mais representativas do urbano em direção àquela típica da paisagem rural, está em consonância com os resultados de pesquisas realizadas em cidades de clima temperado (STEWART, 2011; STEWART e OKE, 2012; STEWART; OKE; KRAYENHOFF, 2014; ALEXANDER e MILLS, 2014) e de clima tropical (CARDOSO e AMORIM, 2018).

Os contrastes térmicos entre as classes com morfologia e cobertura superficial similares oscilaram de $0,5^{\circ} \mathrm{C}$ a $1^{\circ} \mathrm{C}$ da LCZ 3 para a LCZ 7 ao longo dos episódios. Essa variação está inserida no intervalo das diferenças térmicas $\left(\leq 2^{\circ} \mathrm{C}\right)$ entre zonas semelhantes verificado por Stewart (2011) na estruturação do sistema LCZ.

Conforme também relatado pelo autor, o aumento significativo das diferenças de geometria e cobertura da superfície entre as LCZs resulta na ampliação desses contrastes térmicos, podendo exceder $5^{\circ} \mathrm{C}$. Na área de estudo, a maior diferença registrada foi de 5,1ํㅡ entre as LCZ 7 e LCZ D no dia 17 de dezembro.

$\begin{array}{lllll}\text { Caminhos de Geografia } & \text { Uberlândia-MG } & \text { v. 22, n. } 79 & \text { Fev/2021 } & \text { p. 161-179 Página } 172\end{array}$


Com base na temperatura média de cada LCZ na estação de primavera (Figura 9), a maior diferença térmica interzonas foi de $3,2^{\circ} \mathrm{C}\left(\Delta \mathrm{T}_{\mathrm{LCZ}} 3\right.$ - 8D), seguida pelos valores de $3,1^{\circ} \mathrm{C}\left(\Delta \mathrm{T}_{\mathrm{LCZ}} 7-8 \mathrm{D}\right), 3,0^{\circ} \mathrm{C}\left(\Delta \mathrm{T}_{\mathrm{LCZ}}\right.$ - $\left.^{\mathrm{D}}\right)$

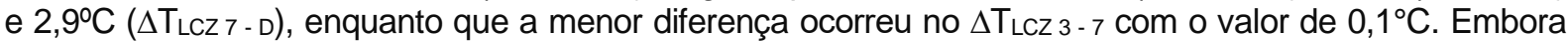
fosse esperado os máximos contrastes de temperatura média entre as distintas classes urbanas com a LCZ D, a extensa área permeável que envolve a LCZ 8D (Figura 8) compensou os efeitos inerentes da fração construída das grandes edificações baixas.

Com o intuito de ampliar a comparação dos resultados obtidos neste estudo com os dados de outras cidades, as intensidades da ICU em Sacramento (MG) também foram determinadas por meio da expressão $\triangle T$ TCZX - D. Na análise da média dos episódios de primavera, a intensidade da ICU derivada dos emparelhamentos das classes selecionadas com a LCZ D variou de - 0,3ํㅡ ( $\triangle \mathrm{TLCZ} 8 \mathrm{D}-\mathrm{D})$ a $3^{\circ} \mathrm{C}\left(\Delta \mathrm{TLCZ} 3_{-\mathrm{D}}\right)$, com valores predominantes no intervalo da categoria de magnitude média (Figura 10).

Todavia, as intensidades diárias entre esses pares de LCZ (Figura 10) revelam a formação de ICUs de magnitude pequena a grande. A relativização das diferenças de temperatura prevista na composição de subclasses estabeleceu a maior quantidade de dias com magnitude pequena nas operações envolvendo as LCZs 3D e 8D.

Em contrapartida, as diferenças substanciais da morfologia e material de superfície instituídas nas respectivas relações das LCZs 3 e 7 com a LCZ D resultaram, respectivamente, na quantificação de medidas representativas das magnitudes média e grande. A intensidade máxima foi registrada no valor de 5,1 ${ }^{\circ} \mathrm{C}$ em 17 de dezembro na notação $\Delta \mathrm{TLCZ} 7$ - D, demonstrando a configuração de uma condição ótima da superfície e da atmosfera na formação de ICU com magnitude grande em cidade de pequeno porte da zona tropical durante a primavera.

Ao considerar as intensidades médias e diárias das ICUs obtidas neste estudo, verifica-se uma expressiva compatibilidade com o padrão de temperatura de algumas combinações LCZs reportado em cidades de baixas e médias latitudes (Figura 11).

Figura 11 - Comparação padronizada das intensidades da ICU entre cidades com base no $\Delta$ TLCz.

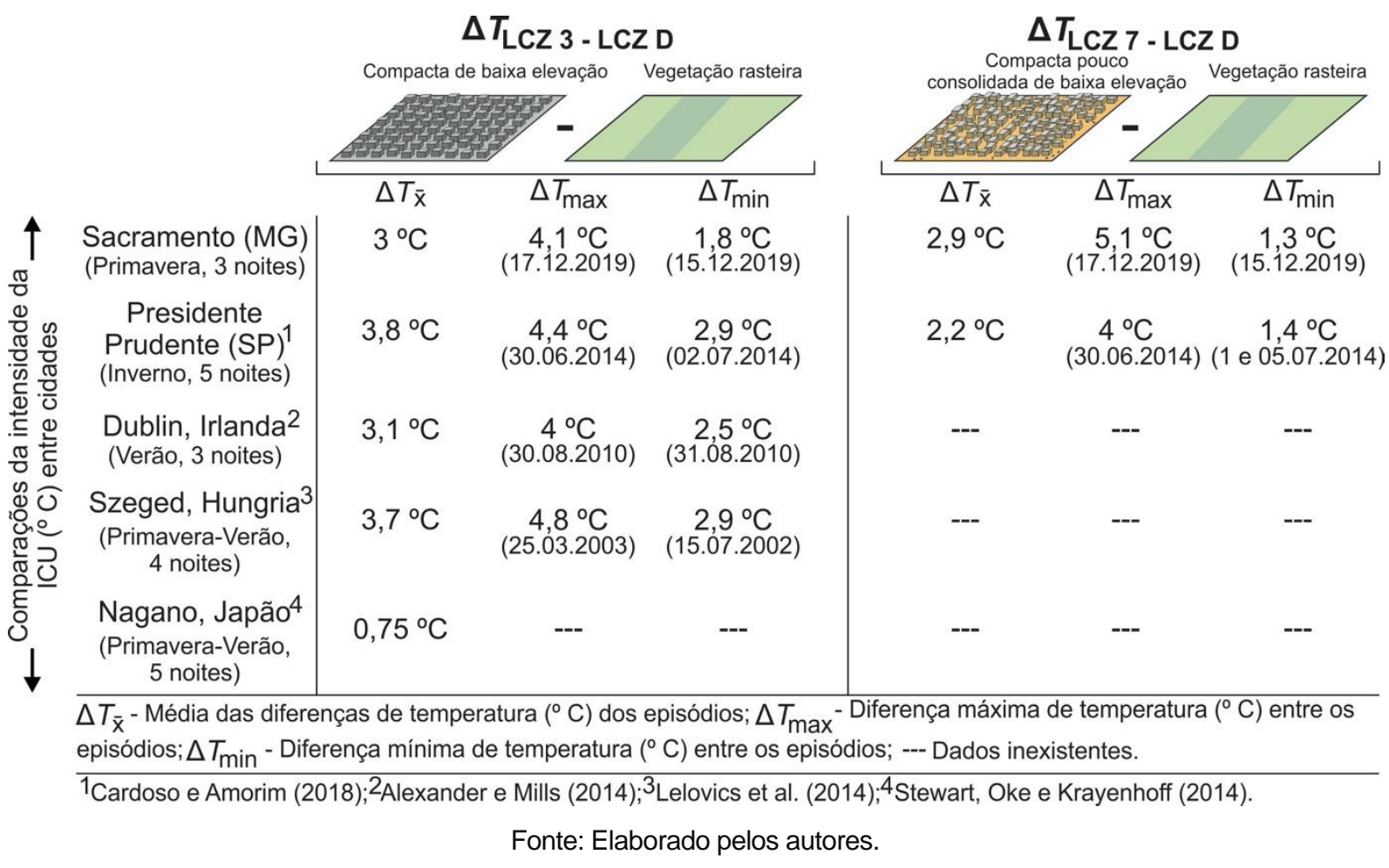

No cenário nacional, as comparações foram restritas às diferenças térmicas de duas relações LCZs ( $\Delta$ TLCZ 3 - D; $\triangle \mathrm{TLCZ} 7$ - D) registradas por Cardoso e Amorim (2018) durante os transectos móveis executados em Presidente Prudente, cidade de médio porte do Oeste Paulista. Ressalta-se que essa restrição decorre de

\begin{tabular}{|c|c|}
\hline Caminhos de Geografia & Uberlândia-MG \\
\hline
\end{tabular}


duas conjunturas: (i) o referido estudo ser o único na literatura da Climatologia Urbana brasileira que incorporou o padrão de representações gráficas do esquema LCZ e; (ii) a reduzida coincidência entre os pares LCZs selecionados nos estudos, que pode ser atribuída às diferenças entre as paisagens urbanas devido ao porte das cidades ou às dificuldades da seleção de distintas zonas em cada sítio urbano sob a devida regulação da influência de condicionantes geoecológicos.

De modo geral, existe uma correspondência razoável na termodinâmica das zonas compactas de baixa elevação consolidadas (LCZ 3) e pouco consolidadas (LCZ 7) em ambos os estudos, tendo em vista o maior aquecimento dessas classes na relação com a LCZ D.

A intensidade obtida no $\Delta T_{L C Z} 3$ - $D$ em Presidente Prudente (SP) foi $0,8^{\circ} \mathrm{C}$ superior à Sacramento (MG) na média, e apresentou valores acima de $0,3^{\circ} \mathrm{C}\left(\Delta \mathrm{T}_{\max }\right)$ e 1,1ํㅡ $\left(\Delta \mathrm{T}_{\mathrm{min}}\right)$ na análise episódica. A pequena diferença de temperaturas nessa comparação pode estar relacionada às distinções das características sazonais do clima tropical, pois as mensurações em Presidente Prudente (SP) foram conduzidas no inverno sob o domínio da Massa Polar Attântica, que configura uma condição mais favorável para aumentar as diferenças entre as referidas LCZs em razão da menor umidade no solo e no ar.

Por outro lado, $0 \Delta T_{L C Z} 7-D$ em Sacramento (MG) foi de 2,9C na média, com máxima diária de $5,1^{\circ} \mathrm{C}$ e mínima de $1,3^{\circ} \mathrm{C}$. Na cidade de Presidente Prudente (SP), por sua vez, os valores alcançados foram, respectivamente: $2,2^{\circ} \mathrm{C}, 4^{\circ} \mathrm{C}$ e $1,4^{\circ} \mathrm{C}$. À medida que os metadados da LCZ 7 em Presidente Prudente (SP) demonstram que a sua composição está mais consolidada em relação ao arranjo de Sacramento (MG), admite-se que a maior heterogeneidade das propriedades de superfície dessa LCZ na última cidade influencia no aumento da variabilidade de temperatura.

Dentre esses padrões de intensidade das ICUs em Sacramento (MG), evidencia-se que os dados da relação entre a $L C Z 3$ e a $L C Z D\left(\Delta T_{\bar{x}}: 3^{\circ} \mathrm{C} ; \Delta T_{\max }: 4,1^{\circ} \mathrm{C} ; \Delta T_{\min }: 1,8^{\circ} \mathrm{C}\right)$ são equiparados às diferenças de temperatura mensuradas nesse $\Delta \mathrm{T} L \mathrm{CZ}$ em cidades de clima temperado (Figura 11) por meio de dados extraídos da realização de transectos móveis.

Alexander e Mills (2014) registraram um valor médio de 3,1ํㅡ nessa combinação em Dublin, na Irlanda. Em noites individuais, a temperatura máxima atingiu o valor de $4^{\circ} \mathrm{C}$ e a mínima de $2,5^{\circ} \mathrm{C}$. Na cidade de Szeged, situada na Húngria, Lelovics et al. (2014) identificaram diferenças térmicas de $3,7^{\circ} \mathrm{C}$ na média e, na análise diária, os valores alcançaram $2,9^{\circ} \mathrm{C}$ no $\Delta \mathrm{T}_{\min }$ e $4,8^{\circ} \mathrm{C}$ no $\Delta \mathrm{T}_{\max }$. Em Nagano, Japão, a temperatura média dessa relação na primavera-verão, reportada por Stewart; Oke; Krayenhoff (2014) no valor $\sim$ de $0,75^{\circ} \mathrm{C}$, foi a mais distante do conjunto de dados dessas cidades.

Apesar da reduzida diferença térmica, os registros do $\triangle T_{L C Z} 3-\mathrm{D}$ nessas cidades e as medidas obtidas em Sacramento (MG) demonstram a influência das estações do ano no ciclo das intensidades da ICU nesse par LCZ. Em Dublin e Szeged, os dados advêm de campanhas de campo conduzidas primordialmente no verão, quando a posição da declinação solar contribui para o maior fornecimento de energia no sistema. Essa condição explicita os pequenos desvios positivos da ICU quantificada nessas cidades em relação à Sacramento (MG). No caso de Nagano, a inundação das áreas da LCZ D para o plantio de arroz durante a primavera-verão afeta a resposta da temperatura nas zonas rurais, evidenciando os efeitos da sazonalidade na definição de marcante contraste com a intensidade média da ICU mensurada entre essas classes nas demais cidades.

De modo geral, a semelhança constatada nos padrões de temperatura entre as cidades nas combinações das LCZs 3 e 7 com a LCZ D corrobora o fundamento de Stewart (2011) acerca do esquema LCZ proporcionar um refinamento da noção sugerida por Oke $(1973$; 1981) para a possibilidade de comparação das magnitudes das ICUs em âmbito regional e continental.

A definição das magnitudes das ICUs pelo $\Delta T_{L C Z}$ minimiza as tentativas de explicação das diferenças entre as cidades com base na simples distinção do tamanho da população, localização dos sítios urbanos e períodos de coleta de dados. Em contrapartida, a adoção dessa expressão estimula a interpretação do processo de formação desse fenômeno pelas propriedades de superfície que integram o sistema de classificação LCZ (STEWART, 2011).

\section{CONSIDERAÇÕES FINAIS}

A avaliação do fenômeno da ICU em Sacramento (MG) sob a estrutura divisional do sistema de classificação LCZ se constitui na primeira aproximação do uso dessa perspectiva em cidade tropical brasileira de pequeno porte. 
A adoção dessa abordagem permitiu a conversão das paisagens da área de estudo em unidades locais que expressam características térmicas distintas como resposta aos parâmetros físicos da estrutura e cobertura da superfície. Assim, admite-se que o mapeamento das LCZs se configura como procedimento preliminar essencial para a condução deste tipo de investigação.

Do ponto de vista metodológico, a proposta de mapeamento empregada neste estudo possui um elevado potencial à categorização do sítio urbano de cidades de pequeno porte em nível de detalhe compatível à concepção do sistema LCZ.

Os resultados da análise do campo termodinâmico das classes mais representativas do universo paisagístico de Sacramento (MG) ao longo da primavera convergiram com os padrões térmicos registrados em estudos fundamentados conforme a presente sistematização, sendo as LCZs compactas de baixa elevação mais aquecidas do que aquela composta predominantemente com cobertura permeável. Essa conjuntura denota à seleção estratégica de sítios que expressam os efeitos térmicos das particularidades da morfologia e do material de superfície das principais LCZs da área de estudo. Ademais, o inerente controle de condicionantes não urbanos externos às LCZs respaldou a avaliação das intensidades das ICUs no intraurbano e na comparação entre distintas cidades.

Ao definir a magnitude das ICUs pelo $\Delta$ TLCZ X - D, os contrastes térmicos entre os pares LCZs com diferenças significativas no arranjo de sua geometria e cobertura da superfície produziram registros no intervalo das categorias média e grande.

A determinação da LCZ D como classe representativa do rural nessa expressão validou a comparação das diferenças de temperatura obtidas em suas combinações com as LCZs 3 e 7 em diferentes cidades. $\mathrm{Na}$ região tropical, as medidas mensuradas em ambos os pares foram equiparadas com os dados de única cidade. Ao mesmo tempo que esse contexto expõe uma lacuna na literatura da Climatologia Urbana tropical, ele fomenta perspectivas promissoras de investigações fundamentadas na aplicação do esquema LCZ para avaliar as magnitudes do efeito das ICUs em cidades tropicais.

Os resultados similares da relação entre a LCZ 3 e a LCZ D com os estudos em cidades de latitudes médias fortalecem a potencialidade do sistema de classificação em promover a generalização das informações atreladas às magnitudes das ICUs em escalas mais amplas. Dentre tais informações, destaca-se o refinamento das explicações sobre a formação do fenômeno, que passam a considerar as propriedades da superfície. As pequenas diferenças nos valores médios e diários das intensidades das ICUs registradas nas cidades comparadas neste estudo manifestam, aparentemente, o efeito da sazonalidade.

Ao considerar a variação da intensidade média das ICUs noturnas conforme a sazonalidade do clima tropical típico, com intensidades menores durante a estação chuvosa e maiores na seca (ROTH, 2007), verifica-se a necessidade de avaliações de episódios representativos das demais estações do ano para o melhor entendimento da configuração desse fenômeno em Sacramento (MG). A execução dessa proposição proporcionará o aumento de dados disponíveis para confirmar a relação ou diferenças sistemáticas dos pares LCZs entre cidades sob distintos tipos de clima.

Para a efetiva comparação das magnitudes das ICUs entre as cidades da mesma zona climática, ou situadas em zonas distintas, recomenda-se a contínua incorporação do arcabouço teórico-metodológico do sistema LCZ nos estudos de Climatologia Urbana. Acredita-se que a cautela acerca dessa diretriz é essencial para as investigações das ICUs, tendo em vista que, por exemplo, os modelos descritivos dessa classificação respaldam uma comunicação consistente dos metadados e dos padrões de temperatura das LCZs.

Por fim, ressalta-se que muitas cidades de pequeno porte do Brasil inseridas em regiões com tendência de crescimento urbano estão sujeitas à deterioração de aspectos fundamentais da vida dos indivíduos (por exemplo, saúde e economia), pois as suas políticas de urbanização são frágeis para lidar com o afluxo de problemas ambientais, com destaque àqueles relacionados ao clima urbano. Assim, é imprescindível a incorporação de preocupações sobre a natureza do clima dessas cidades para subsidiar o desenvolvimento de projetos urbanos visando torná-las resilientes aos impactos climáticos.

No contexto de Sacramento (MG), este estudo representa uma contribuição inicial para a compreensão das magnitudes das ICUs em cidades de pequeno porte que integram um segmento espacial mais amplo denominado pelo IBGE (2017) de Região Imediata de Uberaba (MG). 


\section{AGRADECIMENTOS}

Ao Programa de Pós-doutorado da Unesp, Campus de Presidente Prudente (SP), pela concessão de estágio como pesquisador na Modalidade III (PD-III) ao primeiro autor. Ao Programa Institucional de Bolsas de Iniciação Científica (PIBIC), vinculado à Pró-Reitoria de Pesquisa e Pós-Graduação (PROPPG) da UFTM, pela concessão de bolsa (Edital n. 08/2019) à discente do Curso de Licenciatura em Geografia que assina a coautoria deste trabalho. À Renata dos Santos Cardoso (Unesp, Presidente Prudente) pelas discussões acerca das LCZs.

\section{REFERÊNCIAS}

ALEXANDER, P. J.; MILLS, G. Local Climate Classification and Dublin's Urban Heat Island 2014. Atmosphere, v. 5, n. 4, p. 755-774, out. 2014. https://doi.org/10.3390/atmos5040755

ALONSO, M.S.; LABAJO, J. L.; FIDALGO, M. R. Characteristics of the urban heat island in the city of Salamanca, Spain. Atmósfera, v. 16, n. 3, p. 137-148, jul. 2003.

AMORIM, M. C. de C. T. et al. Características das ilhas de calor em cidades de porte médio: exemplos de Presidente Prudente (Brasil) e Rennes (França). Confins, n. 7, 2009. Disponível em: <https://journals.openedition.org/confins/6070>. Acesso em 9 abr. 2020. https://doi.org/10.4000/confins.6070

. Teoria e método para o estudo das ilhas de calor em cidades tropicais de pequeno e médio porte. 2017. 277 f. Tese (Livre-docência em Geografia) - Faculdade de Ciências e Tecnologia de Presidente Prudente, Universidade Estadual Paulista, Presidente Prudente, 2017.

ANJOS, M. W. B. dos. Orientações climáticas para o planejamento urbano numa cidade costeira do Nordeste do Brasil: Aracaju-SE. 2017. 277 f. Tese (Doutorado em Geografia) - Instituto de Geografia e Ordenamento do Território, Universidade de Lisboa, Portugal, 2017.

BALK, D. et al. Mapping urban settlements and the risks of climate change in Africa, Asia and South America. In: Guzmán, J. M. et al. (Ed.) Population dynamics and climate change. London: International Institute for Environment and Development, 2009. p. 80-103.

BECHTEL, B.; DANEKE, C. Classification of local climate zones based on multiple earth observation data. IEEE Journal of Selected Topics in Applied Earth Observations and Remote Sensing, v. 5, n. 4, p. 1191-1202, ago. 2012. https://doi.org/10.1109/JSTARS.2012.2189873

BECHTEL, B. et al. Mapping Local Climate Zones for a Worldwide Database of the Form and Function of Cities. International Journal of Geo-Information, v. 4, n. 1, p. 199-219, fev. 2015. https://doi.org/10.3390/ijgi4010199

BRAZEL, A. J.; JOHNSON, D. Land use effects on temperature and humidity in the Salt River Valley, Arizona. Journal of the Arizona-Nevada Academy of Science, v. 15, n. 2, p. 54-61, 1980.

CARDOSO, R. dos S.; AMORIM, M. C. de C. T. Urban heat island analysis using the 'local climate zone' scheme in Presidente Prudente, Brazil. Investigaciones Geográficas, n. 69, p. 107-118, jan./jun. 2018. https://doi.org/10.14198/INGEO2018.69.07

CHANDLER, T. J. Temperature and humidity traverses across London. Weather, v. 17, n. 7, p. 235242, jul. 1962. https://doi.org/10.1002/j.1477-8696.1962.tb05125.x

. The climate of London. London: Hutchinson, 1965.

CHIEPPA, J.; BUSH, A.; MITRA C. Using "Local Climate Zones" to Detect Urban Heat Island on Two Small Cities in Alabama. Earth Interactions, v. 22, n. 16, p. 1-22, set. 2018. https://doi.org/10.1175/El-D-17-0020.1

CORBURN, J. Cities, climate change and urban heat island mitigation: localising global environmental science. Urban studies, v. 46, n. 2, p. 413-427, fev. 2009. https://doi.org/10.1177/0042098008099361

DORIGON, L. P. As ilhas de calor urbanas em Jundiaí-SP. 2019. 147 f. Tese (Doutorado em Geografia) - Faculdade de Ciências e Tecnologia de Presidente Prudente, Universidade Estadual Paulista, Presidente Prudente, 2019. 
DUBREUIL, V. et al. Os tipos de climas anuais no Brasil: uma aplicação da classificação de Köppen de 1961 a 2015. Confins, n. 37, 2018. Disponível em: <https://journals.openedition.org/confins/15738>. Acesso em 920 abr. 2020. https://doi.org/10.4000/confins. 15738

FERREIRA, L. S. Vegetação, temperatura de superfície e morfologia urbana: um retrato da Região Metropolitana de São Paulo. 2019. 195 f. Tese (Doutorado em Arquitetura e Urbanismo) - Faculdade de Arquitetura e Urbanismo, Universidade de São Paulo, São Paulo, 2019.

FERREIRA, H. V. L. UGEDA JÚNIOR, J. C. Variação da temperatura da superfície através de imagens ASTER em zonas climáticas locais da cidade de Cuiabá, Brasil. Revista Brasileira de Climatologia, Curitiba, v. 26, p. 393-410, jan./jun. 2020. https://doi.org/10.5380/abclima.v26i0.67546

FIALHO, E. S. Ilha de calor em cidade de pequeno porte: caso de Viçosa, na Zona da Mata Mineira. 2009. 279 f. Tese (Doutorado em Geografia Física) - Faculdade de Filosofia, Letras e Ciências Humanas, Universidade de São Paulo, 2009.

GARTLAND, L. Ilhas de calor: como mitigar zonas de calor em áreas urbanas. São Paulo: Oficina de Textos, 2010.

HEDQUIST, B. C.; BRAZEL, A. J. Urban, residential, and rural climate comparisons from mobile transects and fixed stations: Phoenix, Arizona. Journal of the Arizona-Nevada Academy of Science, v. 38, n. 2, p. 77-87, jul. 2006. https://doi.org/10.2181/1533-6085(2006)38[77:URARCC]2.0.CO;2

HIDALGO, $J$ et al. Comparison between local climate zones maps derived from administrative datasets and satellite observations. Urban Climate, v. 27, p. 64-89, 2019. https://doi.org/10.1016/j.uclim.2018.10.004

HUANG, K. et al. Projecting global urban land expansion and heat island intensification through 2050. Environmental Research Letters, v. 14, n. 11, p. 1-12, nov. 2019. https://doi.org/10.1088/17489326/ab4b71

HUTCHEON, R. J. et al. Observations of the urban heat island in a small city. Bulletin of the American Meteorological Society, v. 48, n. 1, p. 7-9, jan. 1967. https://doi.org/10.1175/1520-0477-48.1.7

INSTITUTO BRASILEIRO DE GEOGRAFIA E ESTATÍSTICA - IBGE. Censo demográfico 2010 características da população e dos domicílios: resultados do universo. Rio de Janeiro, 2011.

. Arranjos populacionais e concentrações urbanas no Brasil. Rio de Janeiro: IBGE, 2016.

Divisão regional do Brasil em regiões geográficas imediatas e regiões geográficas intermediárias. Rio de Janeiro: IBGE, 2017.

IOWA STATE UNIVERSITY - ISU. lowa Environmental Mesonet - IEM. ASOS-AWOS-METAR Data Download: SBUR. c2020. Disponível em: <https://mesonet.agron.iastate.edu/request/download.phtml?network=BR_ASOS>. Acesso em: 11 abr. 2020.

KOPEC, R. J. Further observations of the urban heat island in a small city. Bulletin American Meteorological Society, v. 51, n. 7, p. 602-606, jul. 1970. https://doi.org/10.1175/15200477(1970)051<0602:FOOTUH >2.0.CO;2

LECONTE, F. et al. Using Local Climate Zone scheme for UHI assessment: evaluation of the method using mobile measurements. Building and Environment, v. 83, p. 39-49, jan. 2015. https://doi.org/10.1016/j.buildenv.2014.05.005

. Analysis of nocturnal air temperature in districts using mobile measurements and a cooling indicator. Theoretical and Applied Climatology, v. 130, n. 1-2, p. 365-376, out. 2017. https://doi.org/10.1007/s00704-016-1886-7

LELOVICS, E. et al. Design of an urban monitoring network based on Local Climate Zone mapping and temperature pattern modelling. Climate Research, v. 60, n. 1, p. 51-62, maio. 2014. https://doi.org/10.3354/cr01220 
MAKIDO, Y. et al. Daytime variation of urban heat islands: the case study of Doha, Qatar. Climate v. 4, n, 32, p. 1-14, jun. 2016. https://doi.org/10.3390/cli4020032

MENDONÇA, F. Riscos e vulnerabilidades socioambientais urbanos: a contingência climática. Mercator, Fortaleza, v. 9, n. 1, p. 153-163, dez. 2010.

MONTEIRO, C. A. de F. Análise rítmica em climatologia: problemas da atualidade climática em São Paulo e achegas para um programa de trabalho. Climatologia, São Paulo, n. 1, p. 1-21, 1971.

. A dinâmica climática e as chuvas no Estado de São Paulo - estudo geográfico sob forma de atlas. São Paulo: Instituto de Geografia, Universidade de São Paulo, 1973.

. Teoria e Clima Urbano. São Paulo: USP, 1976.

OKE, T. R. City size and the urban heat island. Atmospheric Environment, v. 7, n. 8, p. 769-779, ago. 1973. https://doi.org/10.1016/0004-6981(73)90140-6

. Canyon geometry and the nocturnal urban heat island: comparison of scale model and field observations. Journal of Climatology, v. 1, n. 3, p. 237-254, jul./set. 1981. https://doi.org/10.1002/joc.3370010304

. Initial guidance to obtain representative meteorological observations at urban sites. Genebra: WMO, 2006. (Instruments and observing methods, 81).

OKE, T. R.; MAXWELL, G. B. Urban heat island dynamics in Montreal and Vancouver. Atmospheric Environment, v. 9, n. 2, p. 191-200, fev. 1975. https://doi.org/10.1016/0004-6981(75)90067-0

ORGANIZAÇÃO DAS NAÇÕES UNIDAS - ONU. World urbanization prospects 2018: highlights. New York: United Nations, Department of Economic and Social Affairs, Population Division, 2019.

PAINEL BRASILEIRO DE MUDANÇAS CLIMÁTICAS - PBMC. Impactos, vulnerabilidades e adaptação às mudanças climáticas. Primeiro relatório de avaliação nacional. Rio de Janeiro: COPPE, 2014. v. 2.

Mudanças climáticas e cidades: relatório especial do Painel Brasileiro de Mudanças Climáticas. Rio de Janeiro: COPPE, 2016.

PAINEL INTERGOVERNAMENTAL SOBRE MUDANÇAS CLIMÁTICAS - IPCC. Climate change 2014: impacts, adaptation, and vulnerability. Part A: Global and sectoral aspects. New York: Cambridge University Press, 2014.

. Climate change 2014: synthesis report. Geneva: IPCC, 2015.

PORANGABA, G. F. O.; TEIXEIRA, D. C. F.; AMORIM, M. C. de C. T. Procedimentos metodológicos para análise das ilhas de calor em cidades de pequeno e médio porte. Revista Brasileira de Climatologia, Curitiba, v. 21, p. 225-247, jul./dez. 2017. https://doi.org/10.5380/abclima.v21i0.48832

PROJETO MAPBIOMAS. Coleção 4.1 da série anual de mapas de cobertura e uso de solo do Brasil. Disponível em:<https://plataforma.mapbiomas.org>. Acesso em: 02 de abril de 2020.

QIU, C. et al. Local climate zone-based urban land cover classification from multi-seasonal Sentinel-2 images with a recurrent residual network. ISPRS Journal of Photogrammetry and Remote Sensing, v. 154, p. 151-162, ago. 2019. https://doi.org/10.1016/j.isprsjprs.2019.05.004

REN, C. et al. Assessment of local climate zone classification maps of cities in China and feasible refinements. Scientific Reports, v. 9, p. 1-11, dez. 2019. https://doi.org/10.1038/s41598-019-55444-9

RIBEIRO, W. C. Impactos das mudanças climáticas em cidades no Brasil. Parcerias estratégicas, v. 13, n. 27, p. 297-322, dez. 2008.

ROTH, M. Review of urban climate research in (sub)tropical regions. International Journal of Climatology, v. 27, n. 14, p. 1859-1873, nov. 2007. https://doi.org/10.1002/joc.1591

SATTERTHWAITE, D. et al. Building climate change resilience in urban areas and among urban 
populations in low-and middle- income nations. London: The International Institute of Environment and Development, 2007. Disponível em: <https://pubs.iied.org/pdfs/10549IIED.pdf >. Acesso em: 9 abr. 2020.

SPRONKEN-SMITH, R. A.; OKE, T. R. The thermal regime of urban parks in two cities with different summer climates. International Journal of Remote Sensing, v. 19, n. 11, p. 2085-2104, 1998. https://doi.org/10.1080/014311698214884

STEWART, I. D. Influence of meteorological conditions on the intensity and form of the urban heat island effect in Regina. The Canadian Geographer, v. 44, n. 3, p. 271-285, set. 2000. https://doi.org/10.1111/j.1541-0064.2000.tb00709.x

Redefining the urban heat island. 2011. 352 p. Thesis (Doctor of Philosophy in Geography) $\overline{\text { Faculty }}$ of Graduate Studies, University of British Columbia, Vancouver, 2011.

Developing a field guide to identify 'local climate zones' in cities. In: INTERNATIONAL CONFERENCE ON URBAN CLIMATE, 10., 2018, New York City, USA. Proceedings... New York City: National Oceanic and Atmospheric Administration (NOAA), The International Association for Urban Climate (IAUC) and the American Meteorological Society (AMS) Board on the Urban Environment, 2018. p. 1-6.

STEWART, I. D.; OKE, T. R. Local climate zones for urban temperature studies. Bulletin of the American Meteorological Society, v. 93, n. 12, p. 1879-1900, nov. 2012. https://doi.org/10.1175/BAMS-D-11-00019.1

STEWART, I. D.; OKE, T. R.; KRAYENHOFF, E. S. Evaluation of the 'local climate zone' scheme using temperature observations and model simulations. International Journal of Climatology, v. 34, n. 4, p. 1062-1080, mar. 2014. https://doi.org/10.1002/joc.3746

SUN, C. Y. et al. Desert heat island study in winter by mobile transect and remote sensing techniques. Theoretical and Applied Climatology, v. 98, n. 3-4, p. 323-335, out. 2009. https://doi.org/10.1007/s00704-009-0120-2

UNGER, J.; LELOVICS, E.; GÁL, T. Local Climate Zone mapping using GIS methods in Szeged. Hungarian Geographical Bulletin, v. 63, n. 1, p. 29-41, 2014; https://doi.org/10.15201/hungeobull.63.1.3

VOELKEL, J.; SHANDAS, V. Towards systematic prediction of urban heat islands: grounding measurements, assessing modeling techniques. Climate, v. 5, n. 41, p. 1-17, jun. 2017. https://doi.org/10.3390/cli5020041

VOOGT, J. A. Urban Heat Island. In: DOUGLAS, I. (Ed.). Encyclopedia of Global Environmental Change. v. 3. New York: John Wiley \& Sons, 2002. p. 660-666.

YAMASHITA, S. Detailed structure of heat island phenomena from moving observations from electric tram-cars in Metropolitan Tokyo. Atmospheric Environment, v. 30, n. 3, p. 429-435, fev. 1996. https://doi.org/10.1016/1352-2310(95)00010-0

Recebido em: 17/04/2020

Aceito para publicação em: 14/08/2020 